\title{
A DNA damage checkpoint in Caulobacter crescentus inhibits cell division through a direct interaction with FtsW
}

\author{
Joshua W. Modell, ${ }^{1}$ Alexander C. Hopkins, ${ }^{1}$ and Michael T. Laub ${ }^{1,2,3}$ \\ ${ }^{1}$ Department of Biology, Massachusetts Institute of Technology, Cambridge, Massachusetts 02139, USA; ${ }^{2}$ Howard Hughes \\ Medical Institute, Massachusetts Institute of Technology, Cambridge, Massachusetts 02139, USA
}

Following DNA damage, cells typically delay cell cycle progression and inhibit cell division until their chromosomes have been repaired. The bacterial checkpoint systems responsible for these DNA damage responses are incompletely understood. Here, we show that Caulobacter crescentus responds to DNA damage by coordinately inducing an SOS regulon and inhibiting the master regulator CtrA. Included in the SOS regulon is sidA (SOS-induced inhibitor of cell division A), a membrane protein of only 29 amino acids that helps to delay cell division following DNA damage, but is dispensable in undamaged cells. SidA is sufficient, when overproduced, to block cell division. However, unlike many other regulators of bacterial cell division, SidA does not directly disrupt the assembly or stability of the cytokinetic ring protein FtsZ, nor does it affect the recruitment of other components of the cell division machinery. Instead, we provide evidence that SidA inhibits division by binding directly to FtsW to prevent the final constriction of the cytokinetic ring.

[Keywords: Caulobacter crescentus; cell division; checkpoint; DNA damage; FtsW]

Supplemental material is available for this article.

Received February 3, 2011; revised version accepted May 3, 2011.

Cells frequently experience genotoxic stresses with potentially mutagenic or fatal consequences. To maintain genome integrity, organisms respond by producing or activating proteins with roles in translesion DNA synthesis, recombination, and repair. In addition, organisms may delay the cell cycle and inhibit cell division until DNA repair and replication are complete. In eukaryotes, these responses are orchestrated by elaborate checkpoint systems that are well understood at the molecular level (Harper and Elledge 2007). The bacterial mechanisms of cell cycle and division control following DNA damage remain only partially understood, and the extent to which different bacterial species use checkpoint systems is unresolved.

In bacteria, DNA damage triggers a change in gene expression called the SOS response (Little and Mount 1982; Butala et al. 2009). This gene expression program is initiated by the autocatalytic cleavage of the transcriptional repressor LexA, an event stimulated by RecA, a multifunctional recombinase and Rad51 homolog. Cleavage of LexA induces the SOS regulon, which includes

${ }^{3}$ Corresponding author.

E-mail laub@mit.edu.

Article is online at http://www.genesdev.org/cgi/doi/10.1101/gad.2038911. a battery of DNA repair genes, some of which are widely conserved in bacteria (Erill et al. 2007). In addition, the Escherichia coli SOS regulon includes sulA, which encodes a cell division inhibitor (Huisman and D'Ari 1981; Mukherjee et al. 1998). SulA directly inhibits polymerization of FtsZ, a GTP-binding tubulin homolog that polymerizes at mid-cell and is crucial to cytokinesis. As SulA is not conserved outside the $\gamma$-proteobacteria, additional mechanisms for inhibiting cell division likely exist in other bacteria.

Cytokinesis in bacteria requires the assembly of a large multicomponent complex of proteins called the divisome. In E. coli, these components assemble in an ordered fashion. The first protein to assemble is FtsZ, which polymerizes at mid-cell into a ring-like structure that is tethered to the cytoplasmic surface of the inner membrane (Lutkenhaus and Addinall 1997; Adams and Errington 2009). In addition to its direct role in constriction, the Z-ring also nucleates assembly of the rest of the divisome, which ultimately coordinates constriction and membrane invagination with construction of a septum, a process that requires localized peptidoglycan synthesis (Errington et al. 2003). The initial formation of a Z-ring is mediated by the proteins FtsA and ZipA, which stabilize FtsZ polymers and anchor the ring to the inner membrane (Adams and 
Errington 2009). In E. coli, additional components are then assembled in a step-wise manner in the order FtsK, FtsQ, FtsL/FtsB, FtsW, FtsI, and FtsN (Goehring and Beckwith 2005; Vicente et al. 2006). The order of assembly is similar, but not identical, in Caulobacter (Goley et al. 2011). Although the assembly of cell division proteins is relatively well characterized, the execution and regulation of cell division remain poorly understood.

A

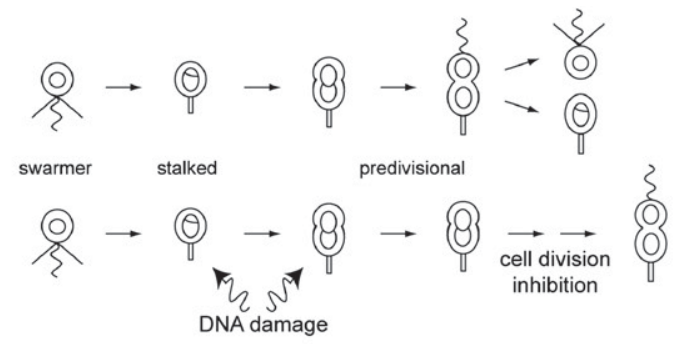

B

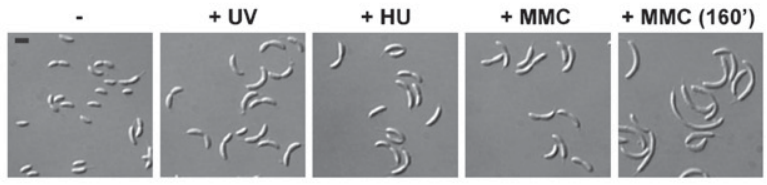

C
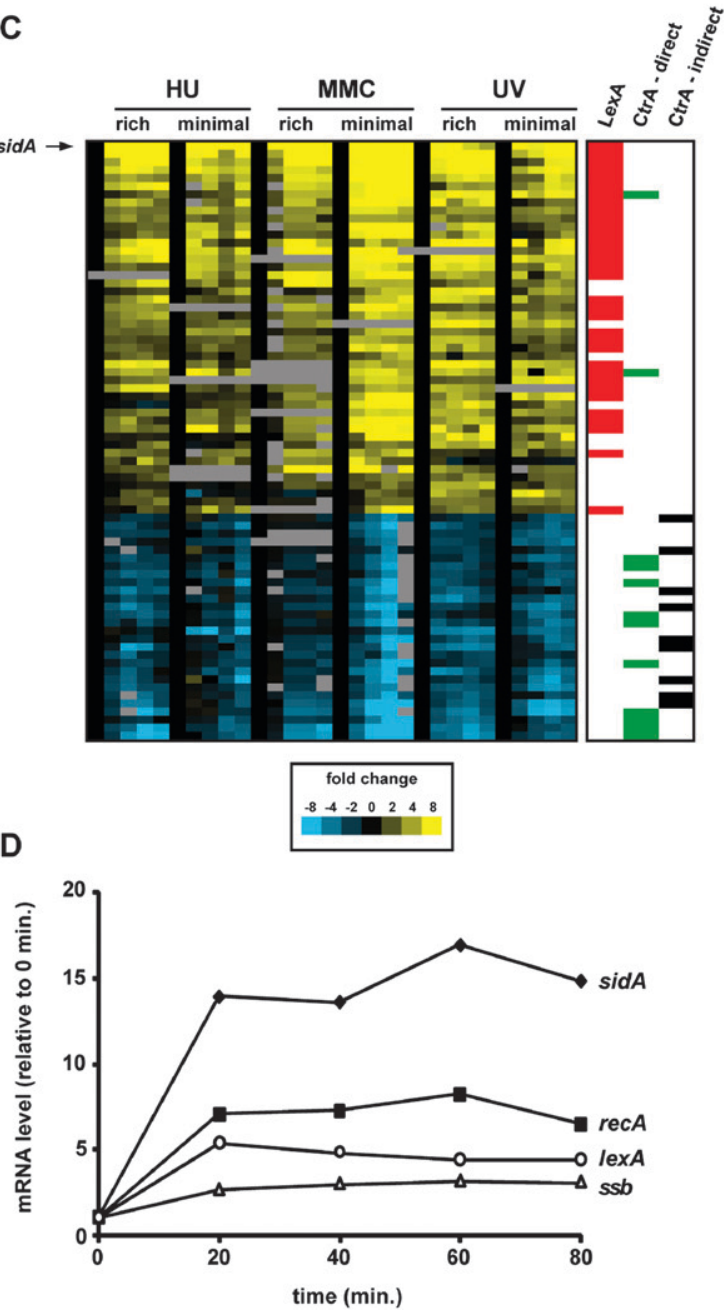

Previous studies of cell division regulation have focused almost exclusively on proteins that modulate Z-ring assembly and stability. For instance, in E. coli, the regulators MinCD and SlmA inhibit FtsZ polymerization at the poles and in proximity to chromosomal DNA, thereby restricting Z-ring formation to mid-cell (Bernhardt and de Boer 2005; Lutkenhaus 2007); MinCD and Noc play analogous roles in Bacillus subtilis (Wu and Errington 2004). FtsZ is also a focal point of regulation following cellular stress. In $B$. subtilis, UgtP coordinates Z-ring assembly with glucose availability (Weart et al. 2007), while MciZ inhibits FtsZ polymerization during sporulation (Handler et al. 2008). In E. coli, DNA damage induces SulA, which inhibits FtsZ polymerization and GTP hydrolysis to prevent cell division (Mukherjee et al. 1998; Justice et al. 2000).

It is unclear whether the numerous essential components of the cytokinetic ring other than FtsZ can also serve as points of control. The SOS-induced inhibitors YneA, DivS, and Rv2719c in B. subtilis, Corynebacterium glutamicum, and Mycobacterium tuberculosis, respectively, appear not to inhibit Z-ring formation (Kawai et al. 2003; Chauhan et al. 2006; Ogino et al. 2008). However, the direct targets of these inhibitors remain unknown.

The $\alpha$-proteobacterium Caulobacter crescentus is an excellent model system for understanding the regulation of cell division. Caulobacter cells are synchronizable, and the cell cycle is accompanied by a series of easily tracked morphological transitions (Fig. 1A). Motile swarmer cells reside in a G1 phase and cannot initiate DNA replication. Swarmer cells then differentiate into stalked cells and, concomitantly, initiate DNA replication. As replication proceeds, cells grow and elongate, build a Z-ring at mid-cell, and eventually form a visible constriction at this future site of cell division. Once S phase completes, the cell can

Figure 1. DNA damage induces global changes in gene expression and inhibits cell division. (A) Schematic of the Caulobacter cell cycle with and without DNA damage. (B) Wild-type CB15N grown to mid-exponential phase was exposed to UV light, HU, or MMC for 80 min or left untreated, and was imaged by differential interference contrast microscopy. Cells exposed to MMC were also examined after $160 \mathrm{~min}$. Bar, $2 \mu \mathrm{m}$. $(C)$ Gene expression profiles of DNA damage-regulated genes in Caulobacter. Profiles are shown for 74 genes significantly changed in expression level after treatment with HU, MMC, or UV light in rich (PYE) and minimal (M2G) media. The column labeled "LexA" indicates with a red box whether a gene has a LexA box upstream. The columns labeled "CtrA-direct" and "CtrAindirect" indicate with a green or black box, respectively, whether a gene is a direct target of CtrA or is indirectly affected by CtrA. For annotation of individual genes and complete data, see Supplemental Figure S1 and Supplemental Table S1. Expression ratios are shown relative to untreated cells and are represented using the color scale shown. Gray blocks indicate missing data. $(D)$ Graph showing induction of sidA after DNA damage, relative to other members of the SOS regulon: recA, lex $A$, and $s s b$. Response curves are the average across all six time courses in $C$. 
divide asymmetrically to produce a stalked cell that immediately reinitiates DNA replication and a swarmer cell that must again differentiate before initiating.

How Caulobacter delays cell division after DNA damage is unknown. As noted, Caulobacter does not encode a homolog of SulA or other known SOS cell division inhibitors. The disruption of DNA replication was shown to down-regulate the activity of CtrA, a cell cycleregulated transcription factor that normally promotes the expression of ftsA and ftsQ (Wortinger et al. 2000). However, it is unknown whether the inhibition of CtrA is either necessary or sufficient to delay cell division following DNA damage.

Here, we identify sidA (SOS-induced inhibitor of cell division A), which encodes a small inner membrane protein that is strongly up-regulated following DNA damage. Overproducing SidA is sufficient to inhibit cell division, suggesting it plays an analogous role to SulA in E. coli. However, unlike SulA, SidA does not interfere with the assembly of the Z-ring or the recruitment of other essential cell division components. Instead, SidA inhibits constriction by interacting directly with FtsW and FtsN. Furthermore, mutations that suppress the lethality of overproducing SidA map to ftsW and ftsI. We present evidence that FtsW, FtsI, and FtsN form a subcomplex within the cytokinetic ring. Although these proteins have been implicated in septal peptidoglycan synthesis, SidA does not appear to inhibit this activity. Our results instead suggest a second role for these proteins in triggering the final constriction of the cytokinetic ring, an activity that is inhibited by SidA. The FtsW/I/N subcomplex thus represents a key regulatory node within the cell division machinery, and SidA is, to our knowledge, the first endogenous cell division inhibitor with a known binding target other than FtsZ.

\section{Results}

DNA damage induces cell cycle arrest and a change in global transcription patterns

To investigate the mechanisms coupling DNA integrity and replication status with cell division, we first analyzed the response of Caulobacter cells to mitomycin C (MMC) and ultraviolet light (UV), which damage DNA, and to hydroxyurea (HU), which disrupts DNA replication by depleting nucleotide pools. Each treatment caused cells to transiently arrest the cell cycle; cells continued to elongate but failed to divide (Fig. 1B). Using wholegenome microarrays, we analyzed global changes in gene expression after each perturbation. Wild-type cells were grown to mid-exponential phase in either rich medium or minimal medium and were exposed to one of the three agents (MMC, UV, or HU). Samples were collected immediately prior to treatment and every $20 \mathrm{~min}$ up to $80 \mathrm{~min}$. RNA from each time point was compared with RNA from the pretreatment sample on DNA microarrays.

A total of 160 genes, or nearly $5 \%$ of the annotated genes in Caulobacter, were significantly induced or re- pressed during at least one of these six time courses (for complete data, see Supplemental Table S1). To identify candidate regulators of cell division, we focused on the gene expression changes that were common across all conditions. We found that 74 genes changed consistently across the six time courses, with 28 being down-regulated and 46 being up-regulated (Fig. 1C; Supplemental Fig. S1). Of the 28 genes consistently repressed, 10 were identified previously as direct targets of the master cell cycle regulator CtrA, and nine others are likely indirect targets, as they showed significant decreases in expression in $c t r A^{t s}$ strains (Laub et al. 2002). A previous study demonstrated a similar down-regulation of two CtrA targets, $f t s Q$ and $f t s A$, after HU treatment (Wortinger et al. 2000). We also found that $f t s Q$ mRNA levels dropped after DNA damage, but just missed the thresholds set for inclusion, while the probe for ftsA did not provide reliable data.

\section{Identification of sidA, a novel SOS-induced cell division inhibitor}

Inhibiting CtrA may help block cell division by decreasing the expression of fts $Q$ and ftsA. However, many bacteria induce genes-such as sulA in E. coli and yneA in $B$. subtilis-following DNA damage that post-transcriptionally inhibit cell division (Huisman and D'Ari 1981; Kawai et al. 2003). As noted, the Caulobacter genome does not contain homologs of these genes. To identify a damage-inducible cell division inhibitor, we examined our expression data for genes that (1) are rapidly and strongly up-regulated following DNA damage, (2) are predicted members of the SOS regulon based on the presence of a consensus LexA-binding site /da Rocha et al. 2008), and (3) have no known or predicted role in DNA repair. Based on these criteria, we identified CC1927, which we named $\operatorname{sidA}$, which has a predicted LexAbinding site in its promoter region and is induced nearly 14-fold within 20 min of DNA damage (Fig. 1D). sidA is predicted to encode a highly hydrophobic 40 -amino-acid protein lying 39 bases upstream of the replicative DNA polymerase III $\alpha$ subunit $(d n a E)$. Despite their close proximity, dnaE and sidA are likely not cotranscribed, as the expression levels of $d n a E$ and sidA are not strongly correlated in the experiments here or reported previously (Laub et al. 2000).

\section{SidA is the principal SOS-induced cell division inhibitor}

To explore the function of $\operatorname{sidA}$, we created a strain in which all but the first and last three amino acids of the originally annotated coding sequence were deleted. This $\Delta$ sidA strain showed no obvious growth or morphological defects in standard rich (Fig. 2A-B) or minimal medium, suggesting that $\operatorname{sid} A$ is dispensable in undamaged cells.

To assess the ability of $\Delta$ sidA cells to withstand DNA damage, we first tested the growth of wild type and $\Delta$ sidA on plates containing increasing concentrations of the 
A

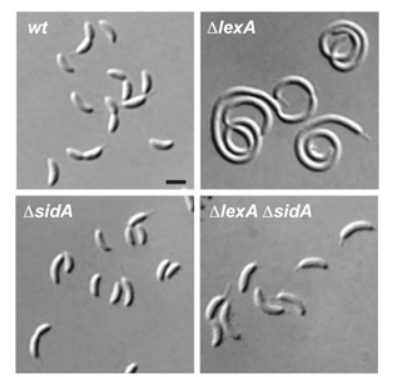

C

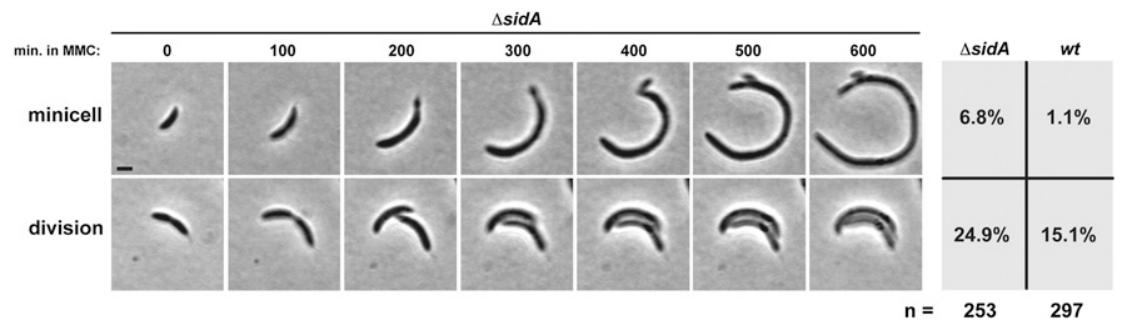

B

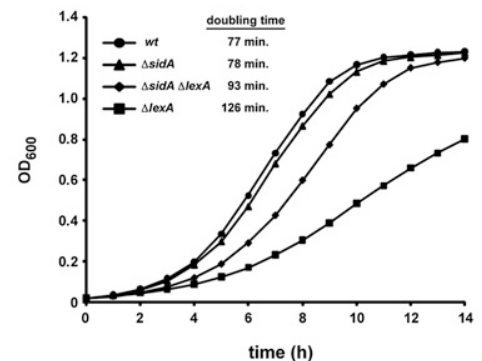

Figure 2. $\operatorname{sidA}$ is the primary SOS-induced cell division inhibitor. $(A, B)$ Micrographs $(A)$ and growth curves $(B)$ of wild-type, $\Delta$ lex $A, \Delta$ sidA, and $\Delta l e x A \Delta$ sidA cells grown in rich medium. Bar in the top left panel, 2 $\mu \mathrm{m} .(C) \Delta \operatorname{sidA}\left(\right.$ tet $\left.^{\mathrm{R}}\right)$ cells were placed on agarose pads containing MMC and imaged for up to $600 \mathrm{~min}$. Examples of minicell formation resulting from division near a cell pole or division at mid-cell are shown. The percentage of cells that produce minicells or divide medially are shown on the right and are compared with wild-type cells treated identically.

damaging agent MMC. Under such conditions of DNA damage, $\Delta$ sidA cells showed no major viability defect (data not shown). To better characterize the DNA damage response of $\Delta$ sidA, we used time-lapse microscopy to monitor cells grown on agarose pads containing MMC (Fig. 2C). For both wild-type and $\Delta$ sidA, we tracked $>250$ individual cells from three independent movies, noting for each cell its initial cell cycle stage and subsequent cell division behavior. Among cells that had yet to initiate division when first placed on the pad, $24.9 \%$ of $\Delta$ sidA cells divided compared with $15.1 \%$ of wild-type cells. We also observed a sixfold increase in the number of minicells in $\Delta$ sidA populations, which resulted from ectopic cell divisions occurring near the cell poles (Fig. 2C). SidA thus appears to help prevent inappropriate cell division events following DNA damage at both mid-cell and the poles.

Although these data indicate that SidA inhibits cell division following DNA damage, most $\Delta$ sidA cells still eventually formed long filaments (Supplemental Movie S1), indicating that an alternative means of division inhibition also functions following DNA damage. Note that sulA in E. coli behaves similarly; it is the primary SOS-induced inhibitor of cell division, but not all cells lacking sulA divide prematurely following DNA damage, presumably due to the action of another cell division inhibitor (Gottesman et al. 1981; Hill et al. 1997).

To determine whether SidA is the primary division inhibitor within the Caulobacter SOS regulon, we created a strain harboring deletions in both $\operatorname{lex} A$ and $\operatorname{sidA}$. The lexA deletion alone results in extreme cellular filamentation and a reduction in growth rate owing to constitutive expression of the SOS regulon, even in the absence of DNA damage (Fig. 2A,B; da Rocha et al. 2008). If SidA is the primary SOS-induced inhibitor of cell division, a deletion of sidA should eliminate or alleviate the phenotypes of a $\Delta l e x A$ strain. Strikingly, we found that deleting $\operatorname{sid} A$ in a $\Delta \operatorname{lex} A$ strain completely suppressed cellular filamentation (Fig. 2A), demonstrating that SidA is the principal SOS-regulated division inhibitor in Caulobacter. Whereas $\Delta$ lexA cells were often 10-20 times the length of wild-type cells, $\Delta$ sidA $\Delta$ lexA cells were nearly indistinguishable from wild type. Deleting sidA also partially suppressed the growth phenotype of a $\Delta \operatorname{lex} A$ strain (Fig. $2 \mathrm{~B}$ ). A complete rescue of growth is likely not possible, owing to the constitutive activation of DNA repair and recombination genes in the $\Delta$ lexA strain. Taken together, our data thus far suggest that $\operatorname{sid} A(1)$ is strongly induced following DNA damage as part of the Caulobacter SOS regulon and (2) plays a role in preventing cell division post-damage.

\section{SidA is sufficient, when overproduced, to inhibit cell division}

Next, we wanted to test whether SidA was sufficient to inhibit cell division in the absence of DNA damage by overexpressing $\operatorname{sid} A$ in undamaged, mid-exponentialphase cells. We fused the annotated sidA coding sequence to the xylose-inducible promoter $\mathrm{P}_{x y l}$ on a high-copy plasmid and transformed this construct into the wildtype strain $\mathrm{CB} 15 \mathrm{~N}$. To overproduce SidA, cells were grown in medium containing xylose. Within $1.5 \mathrm{~h}$, cells were elongated relative to wild type or cells harboring an empty vector. After 3 and $6 \mathrm{~h}$, nearly every cell overproducing SidA had formed a long filament, often with multiple pinch sites that likely represent nascent cell division sites (Fig. 3A,B). These data indicate that SidA is sufficient to inhibit cell division even in the absence of DNA damage, and that $\operatorname{sidA}$ may participate in a DNA damage checkpoint similar to sulA.

Homologs of sidA are often predicted to start at a position corresponding to the second methionine of the originally annotated sidA. Additionally, we noted that, unlike the annotated start site, the second methionine in sidA lies downstream from an apparent ShineDelgarno sequence, suggesting that it is the primary 
A

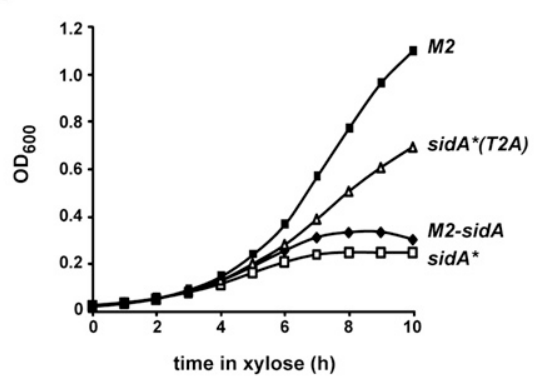

C

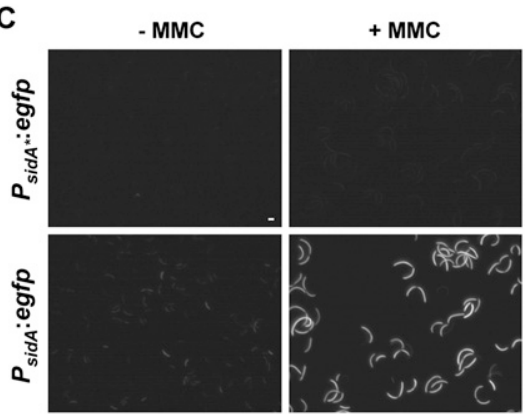

B
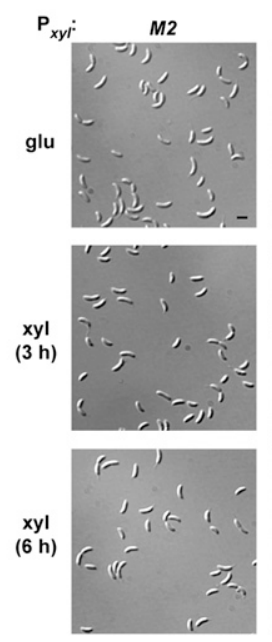
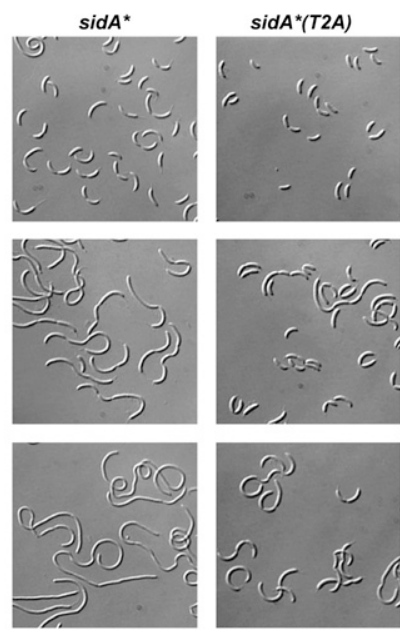

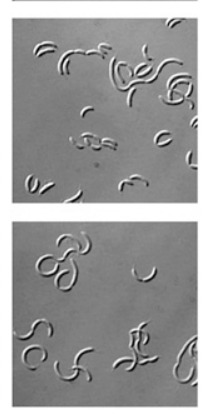

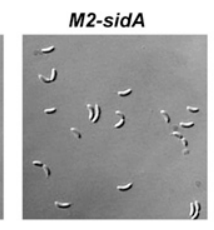
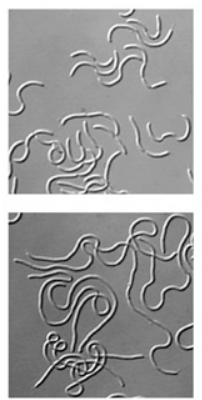

Figure 3. Overproducing SidA is sufficient to inhibit cell division. (A) Growth curve in rich medium of cells carrying a high-copy plasmid on which the xylose-inducible promoter drives expression of the M2 epitope only; sid $A^{*}$, the originally annotated CC1927 ORF; sidA*(T2A), which harbors a mutation in the first annotated start codon; or M2-sidA, in which the M2 epitope is fused to the second start site in the originally annotated CC1927 ORF. (B) Each strain from $A$ was grown to mid-exponential phase in rich medium supplemented with glucose to repress expression of the plasmid-encoded construct. Expression was then induced by adding xylose, and cells were imaged by differential interference contrast (DIC) microscopy after 3 and $6 \mathrm{~h}$. (C) The promoter and leader region of CC1927, up through either the first or second annotated methionine, were fused to the coding region of EGFP to generate $\mathrm{P}_{\text {sidA* }}: e g f p$ and $\mathrm{P}_{\text {sidA }}: e g f p$, respectively. Strains carrying each construct on a lowcopy plasmid were grown in the presence or absence of MMC, and expression was examined by epifluorescence microscopy. Bars, $2 \mu \mathrm{m}$. translational start site. To test this prediction, we mutated the first methionine on the $\mathrm{P}_{\mathrm{xy}}$ : sidA overexpression plasmid from ATG to AAG. For cells harboring this construct, growth in xylose also led to cell division inhibition, suggesting that the second start site is functional (Fig. 3B). The cellular filamentation phenotype was, however, diminished when overexpressing the shorter version of sidA. The more pronounced phenotype seen when overproducing the longer version may indicate that the additional 11 amino acids at the $\mathrm{N}$ terminus either stabilize the protein or somehow render SidA more potent. We favor the former, as overproducing SidA with an $\mathrm{N}$-terminal M2-epitope tag, which is unlikely to enhance potency, led to severe cellular filamentation, as with the original $\mathrm{P}_{x y}$ : sidA construct (Fig. 3B). We could not, however, directly test the stability and size of the native SidA protein, as it is difficult to raise antibodies against such short, hydrophobic proteins.

To more firmly identify the translational start site, we fused the coding sequence for green fluorescent protein, $g f p$, to the $\operatorname{sidA}$ promoter at each of the two putative translational start sites on a low-copy plasmid. Following MMC treatment, only cells bearing the fusion of GFP to the second methionine exhibited significant fluorescence (Fig. 3C). We conclude that SidA translation initiates primarily, and perhaps exclusively, from the second site to produce a 29-amino-acid protein; hereafter, references to SidA imply this shorter version and SidA* refers to the longer form.
SidA does not disrupt divisome assembly or localization

How does SidA inhibit cell division? We first tested whether overproducing SidA affected patterns of gene expression. We compared RNA from cells overproducing M2-SidA for 45 or 90 min with cells grown in noninducing conditions on whole-genome DNA microarrays, but did not observe any significant changes to the SOS or CtrA regulons (data not shown). Overproducing SidA also did not affect chromosome content, as measured by flow cytometry, indicating that SidA does not inactivate CtrA. Instead, SidA likely acts post-transcriptionally to inhibit cell division.

In E. coli, the SOS-induced regulator SulA disrupts polymerization of the cytokinetic ring protein FtsZ (Mukherjee et al. 1998). To determine whether SidA functions similarly, we introduced the $\mathrm{P}_{x y}$ : M2-sidA overexpression plasmid into a strain in which ftsZ-eyfp is expressed from the chromosomal vanillate promoter $\mathrm{P}_{\text {Van. }}$. Vanillate was added to cells $1.5 \mathrm{~h}$ prior to the addition of xylose to allow FtsZ-EYFP to accumulate to sufficient levels for visualization by epifluorescence microscopy. After growth in xylose for $1.5 \mathrm{~h}$, the majority of cells had begun to elongate, but FtsZ foci were still visible at the constriction site (Fig. 4A), indicating that SidA did not disrupt the cytokinetic Z-ring. After 3 and $4.5 \mathrm{~h}$ in xylose, cellular filamentation became more severe, but 
A
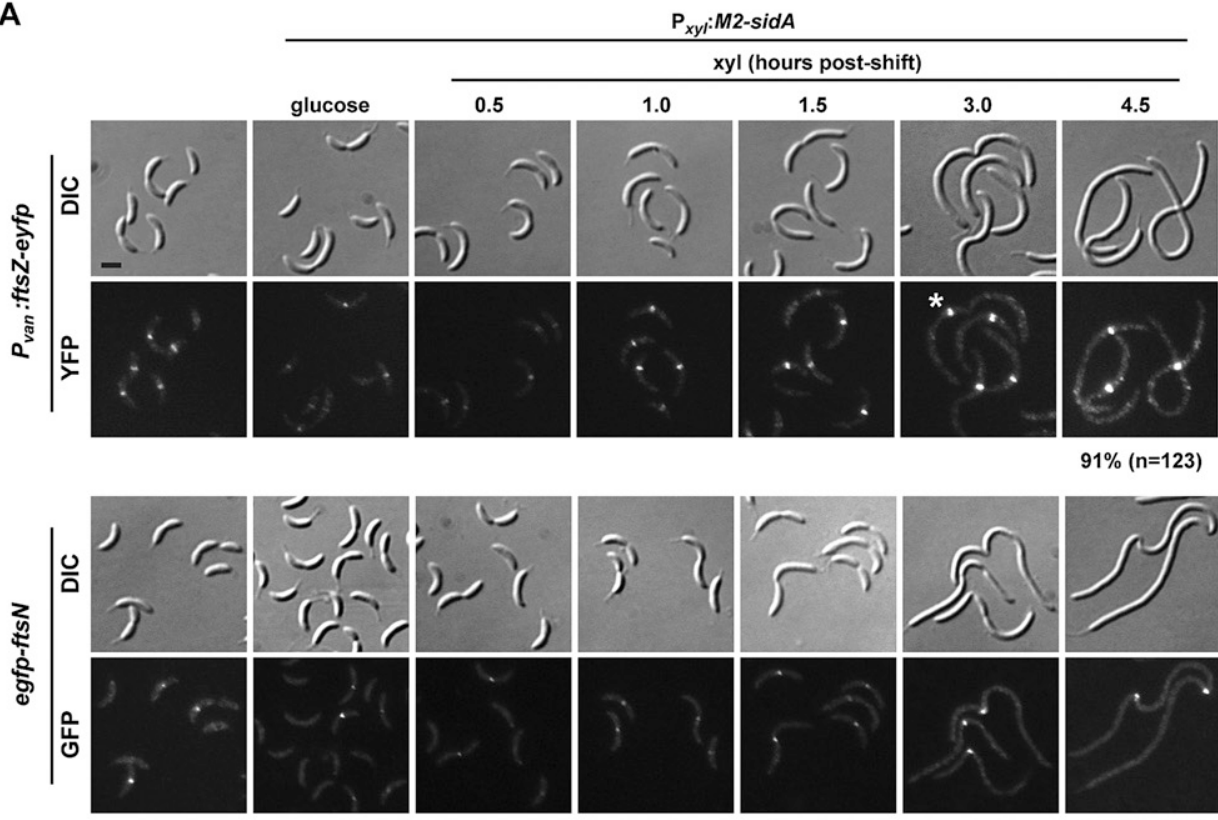

$91 \%(n=123)$

B
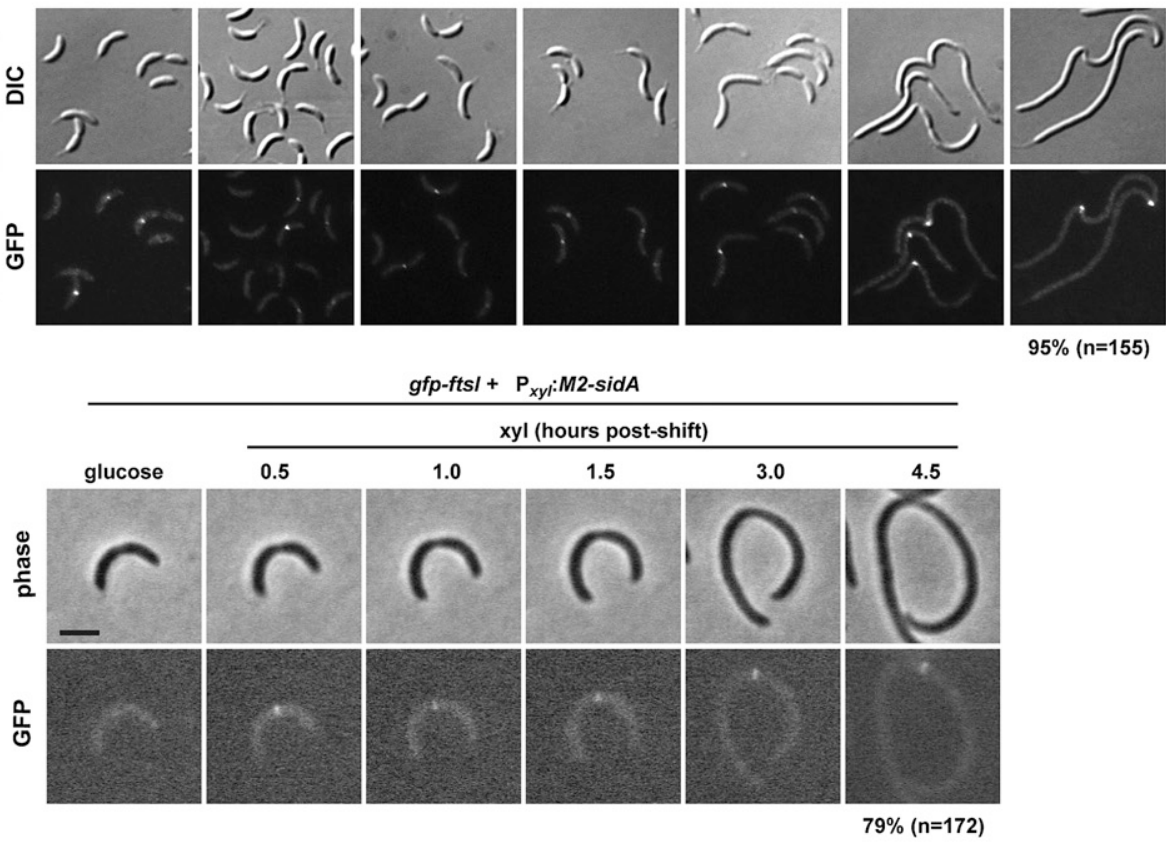

$95 \%(n=155)$

C

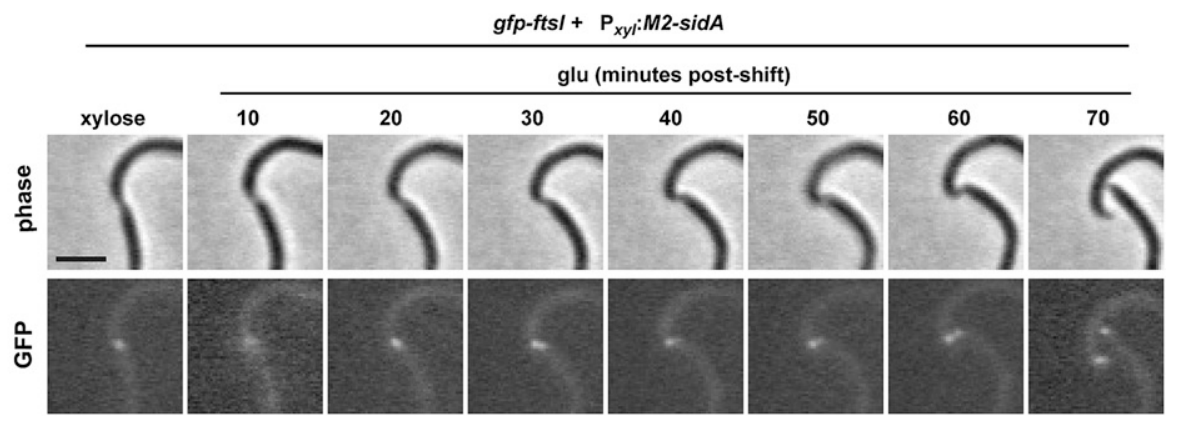

Figure 4. SidA does not prevent assembly of the cell division machinery. (A) Subcellular localization of FtsZ was examined in a strain expressing ftsZ-eyfp from the vanillate-inducible promoter $\mathrm{P}_{\text {van }}$ and overexpressing M2-sidA from a xylose-inducible promoter on a high-copy plasmid. Cells were grown to mid-exponential phase in rich medium with glucose and then shifted to xylose. Vanillate was added $1.5 \mathrm{~h}$ before shifting to xylose. At the times indicated, samples were taken and cells were imaged by DIC and epifluorescence microscopy (top two rows). The white asterisk indicates a FtsZ ring that is no longer associated with a constriction site and so likely moved and reassembled. (Bottom two rows) Localization of FtsN was examined in a strain expressing an egfp-fts $N$ fusion at its native chromosomal locus and overexpressing M2-sidA from a high-copy plasmid. The percentage of cells with foci after $4.5 \mathrm{~h}$ in xylose is shown below the last panel. $(B)$ Localization of FtsI was examined in a strain expressing gfp-ftsI at its native chromosomal locus and overexpressing M2-sidA from a xylose-inducible promoter carried on a high-copy plasmid. Cells were grown to mid-exponential phase in rich medium with glucose and then placed on agarose pads containing xylose to produce M2-SidA. Individual cells were followed by time-lapse microscopy, with phase and epifluorescence images captured at the time points indicated. $(C)$ Cells expressing gfp-ftsI and xylose-inducible $M 2$-sidA were grown in the presence of xylose for $4.5 \mathrm{~h}$ to inhibit cell division and induce cellular filamentation. Cells were then placed on an agarose pad containing glucose to repress M2-sidA expression. Individual cells with localized GFP-FtsI were then followed by time-lapse microscopy, with phase and epifluorescence images captured at the time points indicated. Bars, $2 \mu \mathrm{m}$. 
FtsZ foci were still present (Fig. 4A). In some cells, the FtsZ ring appeared to move a short distance from the original constriction site (Fig. 4A), indicating that FtsZ rings are also able to assemble de novo even in the presence of high levels of SidA. To confirm these results, we used time-lapse microscopy of this same strain grown on an agarose pad containing xylose (Supplemental Movie S2). This analysis confirmed that FtsZ rings typically remain at constriction sites in individual cells well beyond the time normally necessary for septation, although occasionally the Z-ring relocated to a new position along the long axis of the cell body. Collectively, these results demonstrate that SidA does not disrupt the polymerization, assembly, or stability of FtsZ rings.

SidA thus acts downstream from FtsZ assembly to affect cell division. In E. coli and Caulobacter, the cell division machinery assembles in a stepwise manner, with the recruitment of each component to mid-cell requiring recruitment and assembly of prior components (Goehring and Beckwith 2005; Vicente et al. 2006; Goley et al. 2011). Once the divisome is fully assembled, FtsZ constriction and cell envelope septation proceed, although the signals and mechanisms driving these processes are poorly understood. As FtsZ recruitment is one of the earliest steps of cell division, SidA could block the recruitment of a late-arriving cell division protein. Alternatively, SidA may not affect divisome assembly and may instead inhibit the constriction process.

To distinguish between these two possibilities, we examined the localization of the cell division protein FtsN, which is one of the late-arriving essential components recruited to the division site (Costa et al. 2008; Moll and Thanbichler 2009; Goley et al. 2011). The $\mathrm{P}_{x y 1}$ :M2sidA overexpression plasmid was introduced into a strain expressing egfp-fts $N$ from its native, chromosomal locus. When grown in the presence of glucose, EGFP-FtsN foci were seen at mid-cell only in very late, deeply pinched predivisional cells. When grown in xylose to induce SidA production, these FtsN foci remained intact, always localizing at or near the constriction site (Fig. 4A). Similar results were obtained with Venus-FtsW (see below; Supplemental Fig. S3B). The persistence of FtsZ, FtsW, and FtsN foci suggests that SidA does not disrupt the assembly of the cell division apparatus; instead, SidA likely inhibits the active process of constriction.

Despite the persistence of FtsN foci, SidA could somehow prevent the localization of another divisome component while still allowing FtsN assembly. We therefore tested whether SidA overproduction affected the localization of FtsI, another essential, late-arriving cell division protein that participates in septal peptidoglycan synthesis. For these experiments, the $\mathrm{P}_{x y}$ l:M2-sidA overexpression plasmid was introduced into a strain expressing gfp-ftsI from its chromosomal locus. Cells were grown initially in glucose and then shifted to xylose to induce sidA and were followed by time-lapse microscopy. As expected, cells became filamentous owing to the accumulation of SidA. GFP-FtsI foci were seen localized to mid-cell and were maintained through the duration of the $4.5 \mathrm{~h}$ cells were imaged (Fig. 4B).

Taken together, our data suggest that, in cells overproducing SidA, the cell division machinery is fully assembled but somehow inactivated. To test whether cell division can occur once SidA is removed, we examined the behavior of cells harboring the $\mathrm{P}_{x y}$ l:M2-sidA plasmid and expressing $g f p$-ftsI. Cells were grown initially in xylose for $4.5 \mathrm{~h}$ to inhibit cell division and were then returned to medium containing glucose to shut off sidA expression. Within $30 \mathrm{~min}$, many cells were noticeably more pinched at the same sites initially containing GFP-FtsI foci, and, after an hour, these cells had divided (Fig. 4C). Importantly, at time points during and immediately preceding division, the GFP-FtsI foci did not appear significantly brighter than the first time point, regardless of initial intensity. These analyses suggest that SidA does not drive delocalization of FtsI and that cells are poised, once SidA is cleared, to complete cell division.

\section{Mutations in $\mathrm{ftsW}$ and $\mathrm{ftsI}$ suppress the effects of overproducing SidA}

To identify the protein(s) targeted by SidA, we screened for mutations that suppress the growth defect of $\operatorname{sid} A$ overexpression by isolating mutants that form colonies despite SidA overproduction, which is normally lethal. Wild-type cells were transformed with a high-copy plasmid harboring $\mathrm{P}_{x y}$ : $M 2$-sidA and grown on plates containing xylose. This process yielded 80 colonies; an identical transformation with an empty vector yielded tens of thousands of colonies, indicating that suppressors of SidA overproduction are rare. To ensure that suppression did not result from mutations on the sidA overexpression plasmid, we tested whether plasmids from each colony could, in a clean background, still disrupt cell division. We also confirmed by Western blotting that putative suppressor strains still produced high levels of M2-SidA in xylose. In total, we identified nine strains that supported growth despite the production of high levels of M2-SidA. Strikingly, six of the nine suppressors mapped to ftsI or ftsW, both of which encode late-acting, transmembrane components of the cell division machinery. FtsI participates directly in the synthesis of septal peptidoglycan as a periplasmic transpeptidase, while FtsW is a polytopic membrane protein that likely translocates peptidoglycan precursors from the cytoplasm to the periplasm (Holtje 1998; Errington et al. 2003; Mohammadi et al. 2011). The amino acid substitutions in FtsW that suppress sidA overexpression-A31K, F145L, and T180A (found twice)-are predicted to lie adjacent to the cytoplasmic end of transmembrane helix 1, the cytoplasmic end of transmembrane helix 4, and the periplasmic end of transmembrane helix 6, respectively (Fig. 5A). The substitutions identified in FtsI-I45V and F58V-are located in the cytoplasmic tail and the center of FtsI's singletransmembrane helix, respectively (Fig. 5A). For the remaining three suppressor strains, no mutations were found in any known divisome/fts gene. 
A

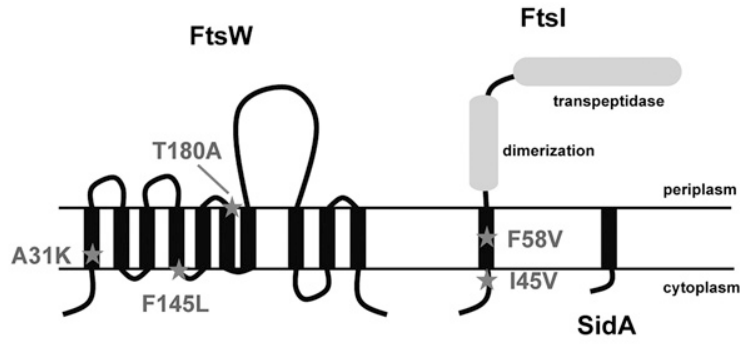

B

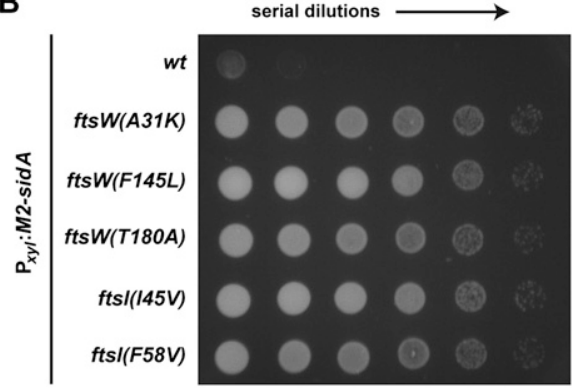

C

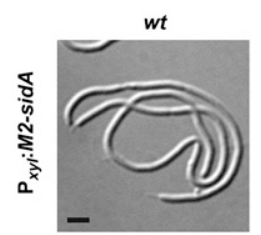

D

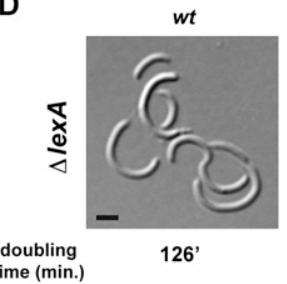

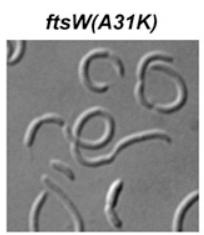

ftsW(A31K)

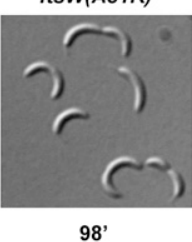

$98^{\prime}$

E

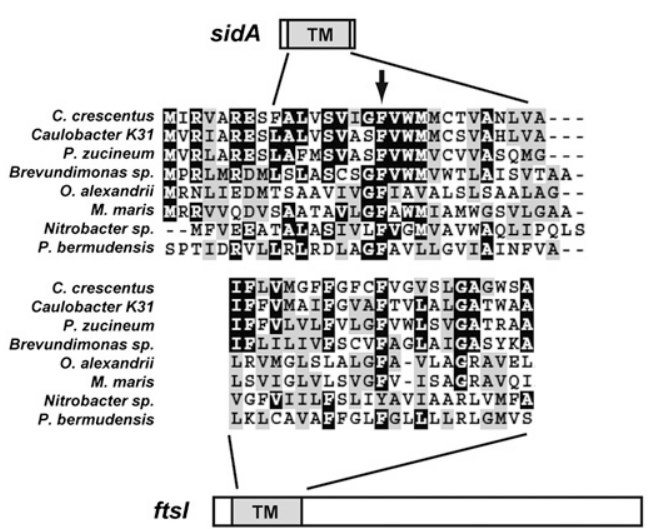

$f t S W(F 145 L)$
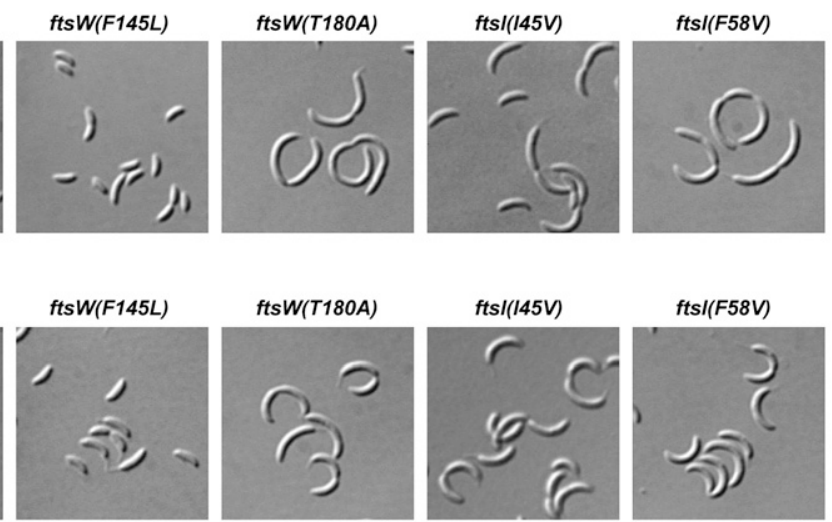

90 '

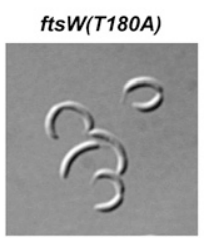

97'

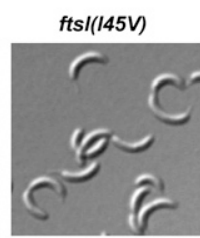

92'

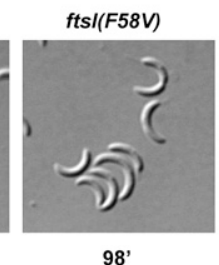

$\mathbf{F}$

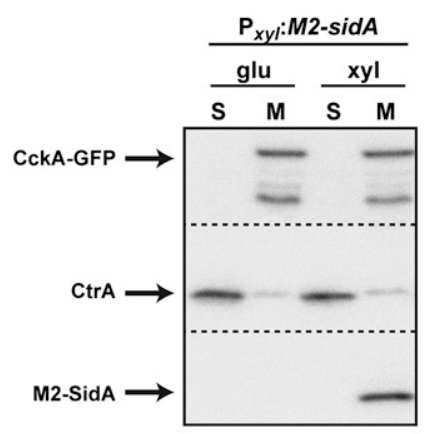

Figure 5. Mutations in ftsW and ftsI suppress the SidA overproduction phenotype. (A) Summary of a sidA overexpression suppressor screen. The location of mutations identified in FtsW and FtsI are indicated on schematics representing the domain structure of each protein. (B) Each suppressor mutation was introduced into a clean wild-type background by allelic replacement, followed by transformation with the M2-sidA overexpression plasmid. Each strain was then grown to mid-exponential phase, and serial dilutions were plated on PYE supplemented with chloramphenicol to maintain the plasmid and with xylose to induce SidA. (C) Cellular morphology of strains harboring each suppressor mutation and overexpressing M2-sidA for $6 \mathrm{~h}$. Bars, $2 \mu \mathrm{m}$. (D) Cellular morphology of strains harboring each suppressor mutation and a deletion of lexA. The doubling time of each strain in rich medium is indicated below the corresponding micrograph. (E) The location of a predicted transmembrane domain within sidA is shown schematically at the top and directly below in an alignment of the coding region of SidA orthologs. The location of a single predicted transmembrane domain within ftsI is shown schematically at the bottom and directly above in an alignment of the transmembrane domains of FtsI orthologs. The alignments are aligned to each other, using the last predicted amino acid as an anchor point. The arrow indicates a conserved phenylalanine in both alignments. Black and gray shading indicate residue conservation and similarity, respectively, found at that position in $>50 \%$ of aligned sequences. $(F)$ Subcellular fractionation of cells overexpressing $M 2$-sidA from a xylose-inducible promoter on a high-copy plasmid for $1.5 \mathrm{~h}$ and expressing cckA-gfp from the chromosome. Samples from cells grown in either glucose or xylose, as indicated, were fractionated into soluble (S) and membrane $(\mathrm{M})$ fractions. Samples were separated by SDS-PAGE, transferred to a PVDF membrane, cut into three pieces, and probed with antibodies specific for GFP, CtrA, or the M2 epitope. 
Each $f$ ts $W$ and $f t s I$ suppressor mutation was introduced into a clean wild-type genetic background by allelic replacement, and no growth or morphological phenotypes were seen during growth in rich medium (Supplemental Fig. S2). We then transformed each strain with the M2sidA overexpression plasmid and inoculated serial dilutions on rich-medium plates containing xylose. Each suppressor mutation conferred a significant growth advantage on xylose as compared with wild-type cells transformed with the same plasmid (Fig. 5B), and each mutation significantly reduced the cellular filamentation that results from overexpressing sidA (Fig. 5C). Each mutation also significantly reduced the cellular filamentation of a $\triangle$ lexA strain (Fig. 5D), which, as noted (see Fig. 2), is strictly dependent on sidA. The FtsW(F145L) and FtsI(I45V) mutations led to the most complete suppression of both growth and morphological phenotypes (Fig. 5C,D). These results suggest that SidA inhibits cell division at a late stage by modulating an activity of FtsW or FtsI.

\section{SidA resides in the inner membrane and interacts directly with FtsW and FtsN}

As the suppressors of sidA overexpression mapped near or within the transmembrane domains of FtsW and FtsI, we considered whether SidA is also localized to the inner membrane. An analysis using TMHMM (Krogh et al. 2001) predicted that residues 9-29 of SidA constitute a transmembrane domain. In the middle of this domain is a highly conserved phenyalanine; a conserved phenylalanine is also found in the middle of the transmembrane domain of FtsI, which was also the site of the mutation F58V in FtsI that suppressed sidA overexpression (Fig. 5E).

To determine the subcellular localization of SidA, we fractionated cells overproducing M2-SidA and probed both membrane and soluble fractions with an $\alpha-M 2$ antibody. SidA was found exclusively within the membrane fraction after $1.5 \mathrm{~h}$ of overproduction (Fig. 5F). As controls, we confirmed that the cytoplasmic response regulator CtrA was found predominantly in the soluble fraction, while the sensor histidine kinase CckA was found exclusively in the membrane fraction.

To determine whether SidA interacts physically with FtsW, FtsI, or any other divisome component, we used a bacterial two-hybrid system based on the reconstitution of a split adenylate cyclase (Karimova et al. 2005). We found that, of the essential divisome components FtsZ/A/ $\mathrm{K} / \mathrm{Q} / \mathrm{L} / \mathrm{B} / \mathrm{W} / \mathrm{I} / \mathrm{N}$, SidA interacted most strongly with FtsW and to a lesser extent with FtsN (Fig. 6A). Interestingly, FtsW and FtsN also interacted strongly with each other, as reported recently in E. coli (Alexeeva et al. 2010). Although SidA did not interact with full-length FtsI, neither did FtsW (data not shown), as expected based on studies in $E$. coli (Mercer and Weiss 2002). We therefore tested a truncated version of FtsI $($ FtsI $\Delta \mathrm{C})$ lacking its periplasmic catalytic domain. This construct did interact
A

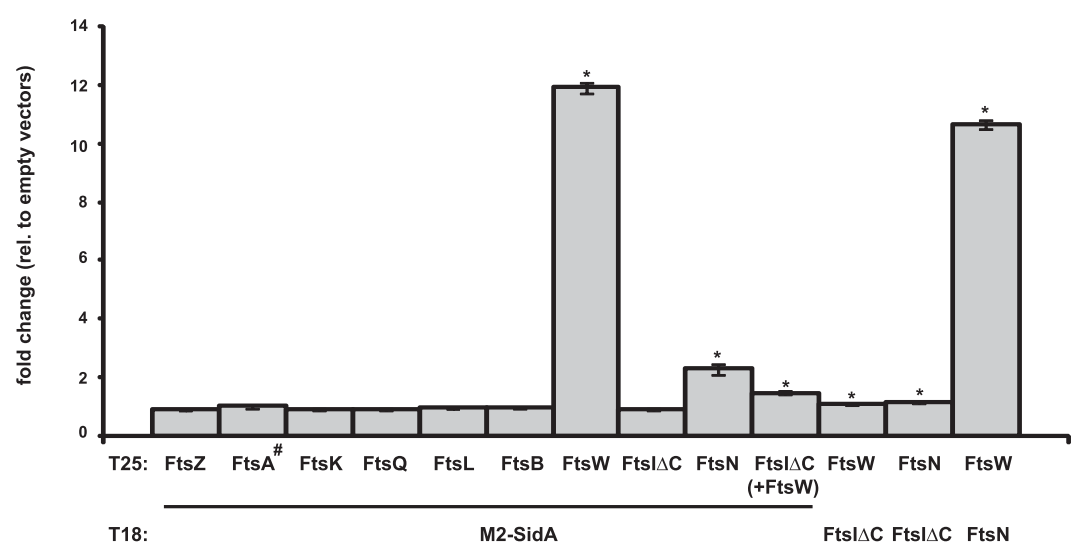

B

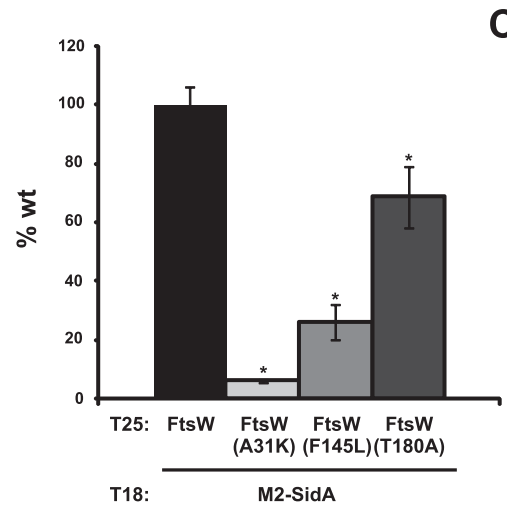

C

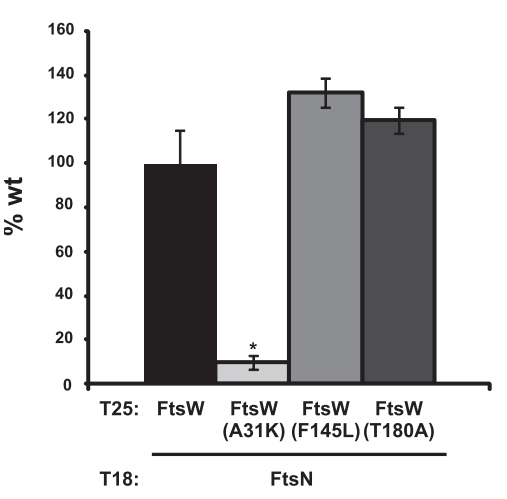

Figure 6. SidA interacts with the latearriving divisome components $\mathrm{FtsW}$ and FtsN. (A) Bacterial two-hybrid analysis of interactions between M2-SidA and cell division proteins fused to $\mathrm{T} 18$ and $\mathrm{T} 25$, as indicated. Interactions were quantified using a Miller assay and are reported relative to empty vector controls, which yielded 60 Miller units. Each interaction was measured in triplicate; error bars represent the standard error of the mean. FtsA ${ }^{\#}$ indicates the FtsA-MalF(TM) fusion described in the Materials and Methods. FtsI $\Delta \mathrm{C}$ was tested alone and while producing untagged FtsW, as indicated. Asterisks indicate a statistically significant difference $(P<0.05$, onesided $t$-test) relative to empty vector controls. $(B, C)$ Bacterial two-hybrid analysis of interactions between M2-SidA $(B)$ or FtsN $(C)$ fused to T18 and mutants of FtsW fused to T25. Interactions are reported as a percentage of that measured for wild-type FtsW with M2-SidA $(B)$ or with wild-type FtsN $(C)$. 
weakly with FtsW and FtsN, but did not interact with SidA. However, an interaction between FtsI $\Delta \mathrm{C}$ and SidA was observed when full-length, untagged fts $W$ was cotranscribed with $f t s I \Delta C$, suggesting that FtsI $\Delta C$ and SidA can bind FtsW simultaneously and likely do not compete for the same site. The strength of the SidA-FtsW and FtsW-FtsN interactions were approximately fivefold lower than a soluble zip-zip homodimerization-positive control. However, divisome components must interact in the membrane, where protein levels and molecular orientations may be more limited than with the cytoplasmic zip-zip interactions. Collectively, these interaction studies demonstrate that (1) FtsW binds to FtsI and FtsN, with these three proteins likely forming a subcomplex within the cytokinetic ring, and (2) SidA directly binds FtsW and FtsN and is brought in close proximity to FtsI via FtsW. We also found that, in cells synthesizing low levels of M2-EGFP-SidA, fluorescent foci were frequently seen at pinch sites within cells (Supplemental Fig. S3A). These foci were often relatively dim, similar to the foci of Venus-FtsW observed in cells synthesizing M2-SidA (Supplemental Fig. S3B) and in contrast to FtsZ-YFP foci (Fig. 4A). These data are consistent with a model in which SidA binds FtsW, a low-abundance divisome component.

We also assessed the ability of the FtsW suppressor mutants to interact with SidA. The suppressor mutations F145L and T180A in FtsW both resulted in a weaker interaction with SidA (Fig. 6B), but did not disrupt interaction with FtsN (Fig. 6C). The FtsW mutant A31K did not interact with SidA or FtsN, suggesting that it may be misfolded or mislocalized in E. coli. Notably, the substitution F145L significantly reduced the binding of FtsW to SidA, and this substitution yielded the most complete suppression of sidA overexpression (Fig. 5C,D). We conclude that SidA likely inhibits cell division through its direct interaction with FtsW, and that mutations in FtsW suppress this inhibition by decreasing its affinity for SidA.

\section{SidA prevents constriction of the Z-ring without disrupting synthesis of nascent septal peptidoglycan}

Collectively, our data indicate that SidA targets an activity, but not the localization, of the late-stage cell division proteins FtsW, FtsI, and FtsN. Each of these proteins is thought to participate in the synthesis of septal peptidoglycan, a critical aspect of cell division. FtsW likely translocates peptidoglycan precursors into the periplasm, where they are incorporated into the nascent septum by transglycosylases and the transpeptidase FtsI (Mohammadi et al. 2011). The role of FtsN is less clear, although it has been proposed to stabilize the divisome and recruit several nonessential proteins involved in cell wall remodeling (Gerding et al. 2009; Rico et al. 2010). Given its affinity for FtsW, SidA could inhibit cell division by preventing the translocation of septal peptidoglycan precursors into the periplasm. To test this possibility, we examined cells stained with fluoresceintagged vancomycin (Van-FL), which is thought to label sites of nascent peptidoglycan synthesis by binding peptidoglycan precursor monomers and growing chains in the periplasm (see the Materials and Methods; Supplemental Fig. S4; Daniel and Errington 2003; White et al. 2010). In wild-type cells, Van-FL weakly stained the cell periphery, with strong foci visible at deep constriction sites in late predivisional cells and weaker transverse bands at mid-cell in early predivisional cells (Fig. 7A). No transverse bands or bright foci of Van-FL were seen in cells $(n=57)$ depleted of fts $Z$ and hence lacking an assembled cytokinesis complex (Fig. 7A). These results are consistent with Van-FL recognizing nascent septal peptidoglycan in C. crescentus.

To test whether mid-cell Van-FL foci are dependent on the presence of FtsW, we examined a ftsW depletion strain in which the only copy of ftsW is controlled by the vanillate-inducible promoter $\mathrm{P}_{\text {van }}$ on the chromosome. Cells grown initially in the presence of vanillate were washed and then grown in the absence of vanillate for $7.5 \mathrm{~h}$ to deplete FtsW. As expected, these cells showed a marked cell division defect, forming long filaments by $7.5 \mathrm{~h}$ that were comparable in length with cells overproducing SidA for $4.5 \mathrm{~h}$ (Fig. 7A). However, unlike cells overproducing SidA, cells depleted of FtsW were noticeably less pinched and formed long, smooth filaments. Accordingly, Van-FL foci were observed only in $10 \%$ of cells $(n=70)$ after $7.5 \mathrm{~h}$ without vanillate (Fig. 7A, arrowheads); these rare foci may arise from incomplete FtsW depletion or compensation by another translocase. We conclude that FtsW is required for cell pinching, cell division, and mid-cell staining with Van-FL, consistent with its proposed role in translocating peptidoglycan precursors to the periplasm.

To examine the effects of SidA on Van-FL staining, we synchronized cells containing the M2-sidA overexpression plasmid and released swarmer cells into either glucose or xylose. In glucose, transverse bands and foci of Van-FL were seen in predivisional cells; after $90 \mathrm{~min}$, these cells had divided and the daughter cells did not have foci, as expected (Fig. 7B). In xylose, bands and foci of Van-FL were also seen in predivisional cells despite the overproduction of SidA (Fig. 7B). After 95 min, cells grown in xylose had not divided and most cells still contained a focus of Van-FL at mid-cell. We also examined a mixed population of cells overproducing SidA for $4.5 \mathrm{~h}$ and found that Van-FL foci were seen at pinched sites in $70 \%(n=83)$ of these filamentous cells (Fig. 7C). Although we cannot rule out that SidA has a mild effect on the flippase activity of FtsW, these data suggest that SidA likely does not inhibit cell division by abolishing the synthesis of septal peptidoglycan. Instead, our results collectively suggest that the FtsW/I/N subcomplex is critical in triggering the final stages of cytokinesis, and that SidA blocks this step of cell division through a direct interaction with FtsW.

\section{Discussion}

Following DNA damage, cells typically must inhibit cell division to allow time for DNA repair. In bacteria, the paradigm for damage-induced inhibition of cytokinesis has been the depolymerization of FtsZ by SulA (Mukherjee et al. 1998; Justice et al. 2000). However, sulA 
Modell et al.

A

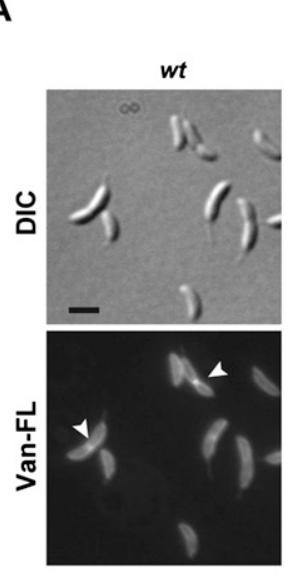

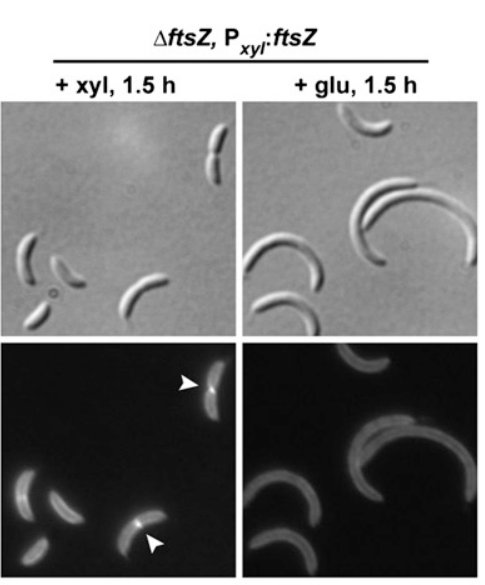

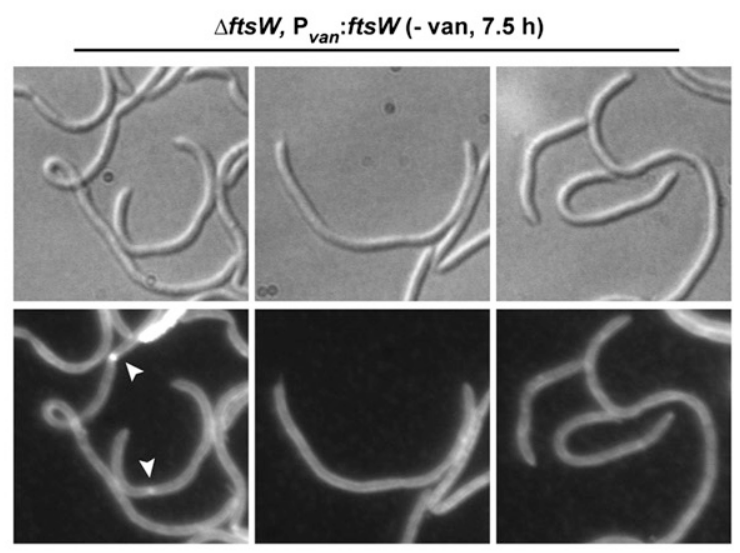

B

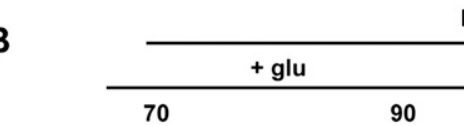

$\mathrm{P}_{x y l}:$ M2-sidA

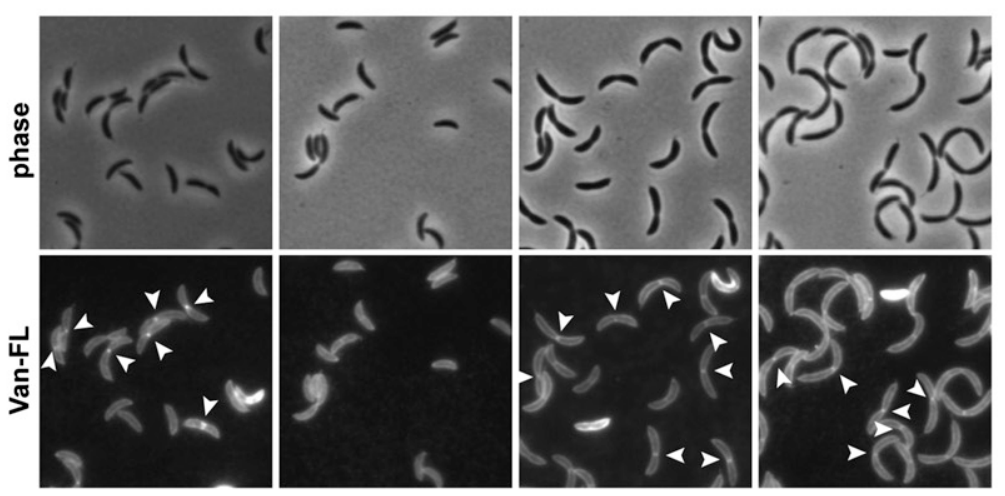

min. post-synchrony

\section{C}

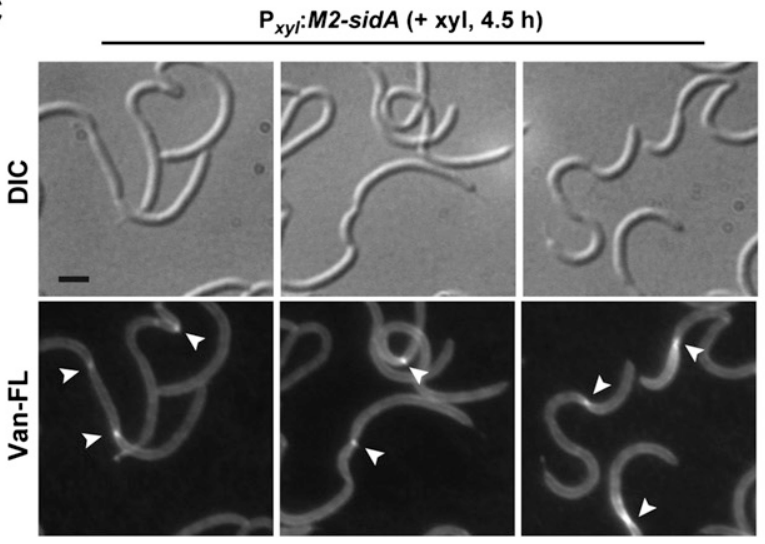

Figure 7. Overproducing SidA does not inhibit the translocation of septal peptidoglycan precursors. $(A)$ Van-FL staining of wild-type, $f t s Z$ depletion, and $f t s W$ depletion. Wild-type cells were grown to mid-exponential phase in rich medium. The fts $Z$ depletion strain was grown to mid-exponential phase in the presence of xylose, washed, and then grown in the presence of xylose or glucose for $1.5 \mathrm{~h}$ before imaging. The $f t s W$ depletion strain was grown to mid-exponential phase in the presence of vanillate, washed, and then grown without vanillate for $7.5 \mathrm{~h}$ before imaging. $(B)$ The M2-SidA overproduction strain was synchronized, released into rich medium containing either glucose or xylose, and imaged at the times indicated. $(C)$ A mixed population of the M2-SidA overproduction strain was imaged after growth in xylose for $4.5 \mathrm{~h}$. In all panels, cells were stained with Van-FL and were imaged by DIC or phase and epifluorescence microscopy. Arrowheads indicate Van-FL staining in transverse bands and foci that are at least 1.5-fold over the cell background (see the Materials and Methods; Supplemental Fig. S4). Bars, $2 \mu \mathrm{m}$. 
homologs are found only in $\gamma$-proteobacteria, and it has been unclear whether other damage-induced inhibitors also target FtsZ. Here, we identified sidA and showed that it encodes the primary SOS-induced cell division inhibitor in C. crescentus. Unlike SulA in E. coli, as well as many other known regulators of cell division, SidA does not directly disrupt FtsZ polymerization or stability. Cells overproducing SidA retain a clear FtsZ ring at mid-cell, but cannot constrict (Fig. 4). Overproducing SidA also did not affect the subcellular localization of FtsW, FtsI, or FtsN, suggesting that SidA does not interfere with divisome assembly. Instead, our results indicate that SidA inhibits constriction by targeting an activity of the late-acting cell division proteins FtsW, FtsI, and FtsN (Fig. 8). Mutations in both ftsW and ftsI were identified in an unbiased screen for suppressors of SidA overproduction. In addition, SidA was found to bind directly to FtsW and FtsN, but, importantly, not to the FtsW suppressor mutants.

What are the activities of FtsW, FtsI, and FtsN in bacterial cytokinesis and how does SidA affect them? These three essential cell division proteins are among the last components recruited to the cytokinetic ring, where they likely form a subcomplex. Furthermore, each component has been implicated in septal peptidoglycan synthesis. FtsW is a polytopic membrane protein and has been proposed to translocate or "flip" peptidoglycan precursors from the cytoplasm to the periplasm, where they are incorporated into existing peptidoglycan strands (Mohammadi et al. 2011). FtsI, also known as penicillinbinding protein 3 (PBP3), harbors transpeptidase activity in its periplasmic domain and cross-links septal peptidoglycan (Spratt 1977). The precise role of FtsN in cytokinesis is unknown, but its essential function resides within its periplasmic linker domain (Moll and Thanbichler 2009). Our results suggest that SidA does not inhibit the putative flippase activity of FtsW. In cells overexpressing $\operatorname{sidA}$, the presence of Van-FL staining at constriction sites indicates that septal peptidoglycan precursors are present in the periplasm. SidA could target septal peptidoglycan modification activities of FtsW, FtsI, or FtsN that occur in the periplasm after precursor flipping. However, this possibility seems unlikely, given that SidA comprises only 29 amino acids and so lies almost entirely within the inner membrane. Moreover, the mutations in ftsW and ftsI that suppress sidA overexpression are all found within the transmembrane or cytoplasmic domains.

Our results suggest that, in addition to controlling septum synthesis, FtsW, FtsI, and FtsN may also play central roles in triggering the final constriction of the cytokinetic ring, and that SidA may disrupt this function to inhibit cell division. As noted, we identified mutations in $f t s W$ and $f t s I$ that suppress the effects of overproducing SidA. The substitutions in FtsW likely suppress by preventing the binding of SidA to the cytokinetic ring. However, a similar explanation does not hold for the substitutions in FtsI, as SidA did not bind FtsI in our two-hybrid system. Instead, these mutations may allow FtsI to help trigger constriction even when SidA is bound to FtsW, thereby bypassing cell division inhibition. FtsI has also been suggested to serve as a checkpoint signal that triggers Z-ring constriction in E. coli, possibly

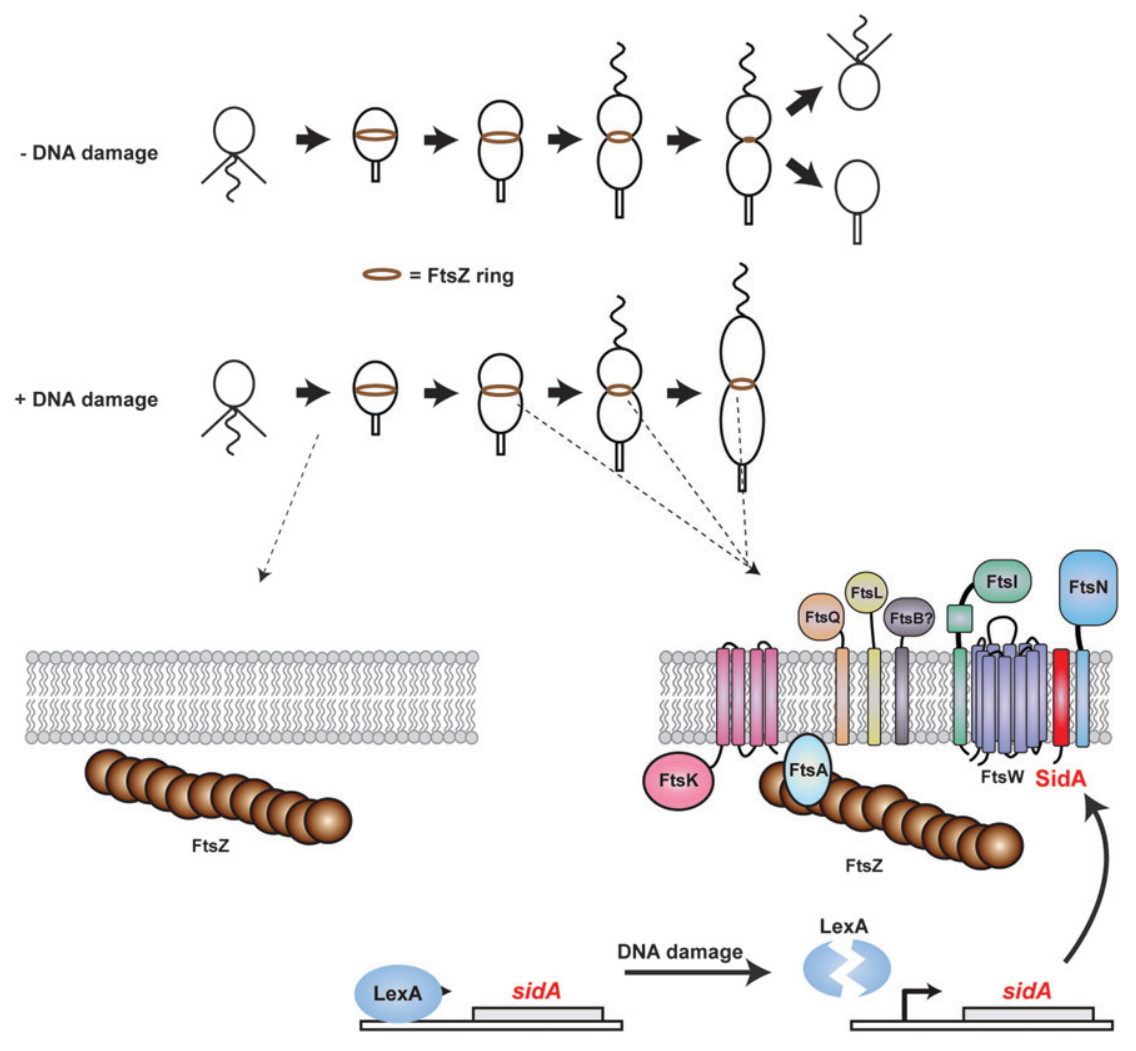

Figure 8. A DNA damage checkpoint regulating cell division in C. crescentus. Model for regulation of cell division by SidA following DNA damage. The schematic at the top shows the Caulobacter cell cycle and indicates the progression of cell division, beginning with assembly and initial stabilization of FtsZ rings in stalked cells, followed by constriction in late predivisional cells, and resulting finally in cell division. When DNA damage occurs, the FtsZ ring is still assembled, but cell division is inhibited while cells continue to elongate. SidA inhibits cell division by inserting into the membrane and binding FtsW and FtsN. The expression of $\operatorname{sidA}$ is under SOS control, and hence is induced following DNA damage and cleavage of the LexA repressor. 
via interactions with FtsA (Corbin et al. 2004), and FtsW and FtsI form a ternary complex with FtsZ in $M$. tuberculosis (Datta et al. 2006). Although we did not observe an interaction between Caulobacter FtsI and FtsA or FtsZ, FtsI may act through an as-yet-unidentified component of the cytokinetic ring. The identification of sidA overexpression suppressor mutations that do not map to the fts genes should prove illuminating in this regard. Finally, we note that FtsW, FtsI, and FtsN may not trigger constriction, and SidA could simply be using FtsW and FtsN as a docking site from which it directly inhibits the activity of another divisome component, such as FtsZ. Although we did not observe strong interactions between SidA and any of the other essential Fts cell division proteins, this possibility cannot be ruled out completely.

The identification of SidA underscores how little is known about the execution of cytokinesis in bacteria. The hierarchical dependencies underlying assembly of the cell division apparatus have been well documented in recent years, largely through the study of fluorescently tagged proteins. While a map of localization dependencies is useful, it remains a significant challenge to define the biochemical activities of each cell division protein and to understand their interdependencies and their roles in regulating cell division.

\section{Is SulA an outlier?}

SulA and the depolymerization of FtsZ has long been the paradigm for regulated cell division inhibition in bacteria. Consequently, the characterization of other SOS-induced cell division inhibitors has focused on Z-ring assembly and stability. However, in many cases, such as YneA in $B$. subtilis (Kawai et al. 2003), DivS in C. glutamicum (Ogino et al. 2008), and Rv2719c in M. tuberculosis (Chauhan et al. 2006), a direct interaction with FtsZ has not been documented. Moreover, in none of these cases did inhibitor overproduction result in complete Z-ring dissociation, as with SulA. In light of our results, we speculate that these inhibitors could target cell division steps downstream from Z-ring assembly or stability, as has been proposed recently for YneA and Rv2719 (Chauhan et al. 2006; Kawai and Ogasawara 2006; Mo and Burkholder 2010). Consistent with this possibility, YneA, DivS, and Rv2719c are each single-pass transmembrane proteins like SidA but in contrast to the cytoplasmic SulA. In addition, Rv2719c and YneA contain periplasmic domains with putative peptidoglycan-binding motifs, and Rv2719c exhibits cell wall hydrolase activity in vitro. It is thus quite plausible that these inhibitors also target FtsI, FtsW, or another late-acting divisome component, almost all of which possess transmembrane and/or periplasmic domains. The three-protein complex SpoIID, SpoIIM, and SpoIIP in B. subtilis is also thought to block cytokinesis at a late stage in mother cells during sporulation (Eichenberger et al. 2001).

Why target divisome components other than FtsZ? We speculate that the regulation of late cell division events may be more effective at inhibiting division in cells that already have fully formed, stable FtsZ rings. Targeting a late-acting divisome component may be easier for the cell than dismantling an existing cytokinetic ring. Interestingly, Z-ring assembly occurs much earlier during the cell cycle in Caulobacter than in E. coli, perhaps necessitating a target other than FtsZ (Quardokus et al. 2001). Alternatively, this strategy may prevent the wasteful disassembly and reassembly of the cell division machinery during periods of transient DNA damage. Modulating the activity of cell division proteins may also be a more effective and reliable means of inhibiting cytokinesis than blocking component localization or assembly. The efficacy of inhibiting the activity of latestage cell division proteins is reinforced by the fact that many antibiotics, such as cephalexin, target FtsI activity to effectively disrupt cell division in many bacteria.

\section{Redundancies in cell division regulation}

Is SidA the only mechanism for inhibiting cell division following DNA damage in Caulobacter? The fact that a sidA deletion almost completely suppressed the cellular filamentation of $\triangle l e x A$ mutants argues that SidA is the primary SOS-induced cell division inhibitor. However, the increase in aberrant cell divisions following DNA damage in $\Delta$ sidA cells was modest and the majority of $\Delta$ sidA cells did not divide, suggesting that additional mechanisms for inhibiting cell division must exist. As noted, a similar situation exists in E. coli, where sulA mutations suppress the filamentation of $\triangle l e x A$ strains but sulA mutants still filament following DNA damage (Hill et al. 1997).

One possible additional mechanism is the damagedependent down-regulation of CtrA, which controls the expression of the cell division genes fts $Q$ and $f t s A$ (Fig. 1B; Wortinger et al. 2000). The down-regulation of CtrA may prevent divisome assembly in cells that have yet to synthesize FtsQ or FtsA, while SidA may block constriction in damaged cells that have already assembled the divisome. Consistent with this model, we found that mixed populations of cells treated with DNA-damaging agents exhibited varying levels of pinching, possibly reflecting whether a divisome was fully formed when DNA damage occurred (Fig. 1B).

The presence of unreplicated DNA at mid-cell following DNA damage may also prevent cell division. Such a mechanism, termed "nucleoid occlusion," has been described in E. coli and B. subtilis, where the proteins SlmA and Noc, respectively, bind throughout the chromosome to inhibit FtsZ assembly in nucleoid-proximal areas (Wu and Errington 2004; Bernhardt and de Boer 2005). In Caulobacter, the nucleoid occlusion model was initially dismissed because Z-rings form when the nucleoid is still present at mid-cell. However, a nucleoid occlusion-like mechanism could exist that inhibits later stages of cell division rather than FtsZ assembly.

\section{Final perspectives}

The discovery of SidA also underscores the increasingly recognized role of small proteins in bacterial regulatory 
responses. Bacterial genomes encode scores of small $\mid<50$ amino acids) proteins that have been missed in genome annotation projects or eluded identification in genetic and proteomic screens. Recent studies have begun to systematically identify these small proteins, and, intriguingly, a disproportionate number are predicted to be single-pass transmembrane proteins that accumulate in stress conditions (Hemm et al. 2008, 2010). In nearly all cases, the functions of these small proteins are unknown, but some could target the cell division machinery like SidA does.

Finally, while cell division in Caulobacter has been known to depend on DNA replication and chromosome segregation (Degnen and Newton 1972), dependencies are not necessarily enforced by dedicated surveillance or checkpoint systems (Hartwell and Weinert 1989). The identification of SidA demonstrates that Caulobacter does, in fact, employ checkpoint systems to regulate its cell cycle under times of stress and DNA damage. In $E$. coli, SulA and UmuD mediate DNA damage checkpoints (Huisman and D'Ari 1981; Opperman et al. 1999), and, in B. subtilis, a developmental checkpoint couples the status of DNA replication to the initiation of sporulation (Burkholder et al. 2001). Cell cycle checkpoints that coordinate the timing and order of cell cycle events to maintain genome integrity thus appear to be a common and powerful regulatory strategy in bacteria, as in eukaryotes.

\section{Materials and methods}

Strains, plasmids, and growth conditions

Strains and plasmids used are listed in Supplemental Table S2, with construction details and growth conditions provided in the Supplemental Material.

\section{DNA microarrays}

RNA expression profiling was done as described previously (Biondi et al. 2006). Complete data sets are provided in Supplemental Table S1. Genes selected for Figure 1 had expression values that increased or decreased by twofold or greater in at least four of the six conditions tested.

\section{Microscopy}

For time-lapse microscopy, cells were immobilized on $1 \%$ agarose pads made with PYE medium. Images were acquired on a Zeiss Axiovert 200M microscope with a $63 \times$ phase or $\alpha$ Fluar $100 \times / 1.45$ objective using an Orca II ER camera. For epifluorescence, illumination was provided by an $\mathrm{HBO} 103$ arc lamp using the following emission/excitation filters: YFP, S500/20x and S535/ 30m; GFP, S470/40x and 520/40m; mCherry, S572/35x and $\mathrm{S} 632 / 60 \mathrm{~m}$. All image capture and processing was done through Metamorph software (Universal Imaging Group).

\section{Immunoblots and biochemical fractionations}

Immunoblots were performed as follows: Samples were normalized in sample buffer to $0.5 \mathrm{OD}_{600} / 50 \mu \mathrm{L}$, resolved on $12 \%$ sodium dodecyl sulfate-polyacrylamide gels, and transferred to polyvinylidene difluoride transfer membrane (Pierce). Membranes were probed with polyclonal rabbit $\alpha$-CtrA and $\alpha$-GFP
(Invitrogen) at a 1:5000 dilution and monoclonal mouse $\alpha$-Flag (Sigma) at a 1:1000 dilution. Secondary HRP-conjugated $\alpha$-rabbit (Pierce) or $\alpha$-mouse (Pierce) were used at a 1:5000 dilution.

Biochemical fractionation was performed as described (Moll and Thanbichler 2009) with several modifications. Samples from each culture were adjusted to total $8 \mathrm{~mL}^{\star} \mathrm{OD}_{600}$ units, washed once with $0.2 \mathrm{M}$ Tris- $\mathrm{HCl}(\mathrm{pH} 8)$, and resuspended in $1 \mathrm{~mL}$ of 60 mM Tris- $\mathrm{HCl}\left(\mathrm{pH}\right.$ 8), $0.2 \mathrm{M}$ sucrose, $0.2 \mathrm{mM}$ EDTA, $200 \mu \mathrm{g} \mathrm{mL}^{-1}$ lysozyme, and $5 \mathrm{U}$ of DNase I. The resuspension was incubated for $10 \mathrm{~min}$ at room temperature, frozen at $-80^{\circ} \mathrm{C}$, thawed, and sonicated for $10 \mathrm{sec}$. Intact cells and chromosomal DNA were pelleted by centrifugation at $4000 \mathrm{~g}$ for $10 \mathrm{~min}$. Membranes were then pelleted by centrifugation at $126,000 \mathrm{~g}$ for $1 \mathrm{~h}$ at $4^{\circ} \mathrm{C}$. Twohundred microliters of the supernatant representing the soluble fraction was diluted in $4 \times$ SDS sample buffer. The membrane pellet was washed once with $0.2 \mathrm{M}$ Tris- $\mathrm{HCl}(\mathrm{pH}$ 8) and resuspended in $200 \mu \mathrm{L}$ of $1 \times$ SDS sample buffer. Equal volumes from each fraction were loaded for immunoblot analysis.

\section{Identification of SidA overproduction suppressors}

Wild-type cells were transformed with plasmid pML1716-sidA and plated on PYE supplemented with chloramphenicol and xylose. Single colonies were grown overnight in PYE containing chloramphenicol and xylose and samples were taken for immunoblots, plasmid preparations, and archiving. To isolate chromosomal suppressor mutations and eliminate mutations arising in the sidA overexpression plasmid, we screened for colonies that met three criteria. (1) We used immunoblotting to check that SidA production in each suppressor strain was similar to that seen in wild-type cells transformed with the pML1716-sidA plasmid and grown in xylose for $1.5 \mathrm{~h}$. (2) Plasmids from the suppressor strains were transformed into wild-type cells and plated on PYE supplemented with xylose or glucose. The presence of thousands of colonies on glucose plates and few colonies on xylose indicated a functional plasmid. (3) Plasmids from the suppressor strains were sequence-verified.

Nine strains fulfilled the three criteria above and were deemed likely to harbor chromosomal suppressors. We sequenced the essential fts genes from each strain. Mutations identified in $f t s W$ and ftsI were then engineered into a clean wild-type background by allelic replacement.

\section{Bacterial two-hybrid analysis}

Two-hybrid complementation assays were performed essentially as described (Karimova et al. 2005). OD $_{420}$ readings were obtained with a Spectramax $340 \mathrm{PC}^{384}$ plate reader (Molecular Devices), and the average rate $\left(\mathrm{dOD}_{420} / \mathrm{dt}\right)$ during the 10 - to 20 min time points was used to calculate enzyme activity.

\section{Van-FL labeling}

Van-FL (Molecular Probes) was prepared in DMSO at $3 \mathrm{mg} / \mathrm{mL}$ and cells were labeled at a final concentration of $3 \mu \mathrm{g} / \mathrm{mL}$ for 20 min. Cells were then pelleted at 13,000 rpm for $8 \mathrm{sec}$, washed in PBS, and imaged directly by DIC or phase and epifluorescence microscopy. Fluorescent bands and foci were measured in Image J (http://rsbweb.nih.gov/ij), and those with intensities at least 1.5fold over the cell background were scored as significant (see also Supplemental Fig. S4).

\section{Acknowledgments}

We thank M. Prasol for help with the expression profiling, and A. Grossman, J. Dworkin, and members of the Laub laboratory for 
comments on the manuscript. We acknowledge M. Thanbichler and C. Jacobs-Wagner for strains. M.T.L. is an Early Career Scientist at the Howard Hughes Medical Institute. This work was supported by an NIH grant (5R01GM082899) to M.T.L. and an NSF predoctoral fellowship to J.W.M.

\section{Note added in proof}

In B. subtilis, the cell division inhibitor Maf was also shown recently to directly target a protein other than FtsZ, called DivIVA (Briley et al. 2011).

\section{References}

Adams DW, Errington J. 2009. Bacterial cell division: assembly, maintenance and disassembly of the $\mathrm{Z}$ ring. Nat Rev Microbiol 7: 642-653.

Alexeeva S, Gadella TW Jr, Verheul J, Verhoeven GS, den Blaauwen T. 2010. Direct interactions of early and late assembling division proteins in Escherichia coli cells resolved by FRET. Mol Microbiol 77: 384-398.

Bernhardt TG, de Boer PA. 2005. SlmA, a nucleoid-associated, FtsZ binding protein required for blocking septal ring assembly over Chromosomes in E. coli. Mol Cell 18: 555-564.

Biondi EG, Skerker JM, Arif M, Prasol MS, Perchuk BS, Laub MT. 2006. A phosphorelay system controls stalk biogenesis during cell cycle progression in Caulobacter crescentus. Mol Microbiol 59: 386-401.

Briley K Jr, Prepiak P, Dias MJ, Hahn J, Dubnau D. 2011. Maf acts downstream of ComGA to arrest cell division in competent cells of B. subtilis. Mol Microbiol doi: 10.1111/ j.1365-2958.2011.07695.x.

Burkholder WF, Kurtser I, Grossman AD. 2001. Replication initiation proteins regulate a developmental checkpoint in Bacillus subtilis. Cell 104: 269-279.

Butala M, Zgur-Bertok D, Busby SJ. 2009. The bacterial LexA transcriptional repressor. Cell Mol Life Sci 66: 82-93.

Chauhan A, Lofton H, Maloney E, Moore J, Fol M, Madiraju MV, Rajagopalan M. 2006. Interference of Mycobacterium tuberculosis cell division by Rv2719c, a cell wall hydrolase. Mol Microbiol 62: 132-147.

Corbin BD, Geissler B, Sadasivam M, Margolin W. 2004. Z-ringindependent interaction between a subdomain of FtsA and late septation proteins as revealed by a polar recruitment assay. J Bacteriol 186: 7736-7744.

Costa T, Priyadarshini R, Jacobs-Wagner C. 2008. Localization of PBP3 in Caulobacter crescentus is highly dynamic and largely relies on its functional transpeptidase domain. Mol Microbiol 70: 634-651.

Daniel RA, Errington J. 2003. Control of cell morphogenesis in bacteria: two distinct ways to make a rod-shaped cell. Cell 113: 767-776.

da Rocha RP, Paquola AC, Marques Mdo V, Menck CF, Galhardo RS. 2008. Characterization of the SOS regulon of Caulobacter crescentus. J Bacteriol 190: 1209-1218.

Datta P, Dasgupta A, Singh AK, Mukherjee P, Kundu M, Basu J. 2006. Interaction between FtsW and penicillin-binding protein 3 (PBP3) directs PBP3 to mid-cell, controls cell septation and mediates the formation of a trimeric complex involving FtsZ, FtsW and PBP3 in mycobacteria. Mol Microbiol 62: 1655-1673.

Degnen ST, Newton A. 1972. Chromosome replication during development in Caulobacter crescentus. J Mol Biol 64: 671-680.

Eichenberger P, Fawcett P, Losick R. 2001. A three-protein inhibitor of polar septation during sporulation in Bacillus subtilis. Mol Microbiol 42: 1147-1162.
Erill I, Campoy S, Barbe J. 2007. Aeons of distress: an evolutionary perspective on the bacterial SOS response. FEMS Microbiol Rev 31: 637-656.

Errington J, Daniel RA, Scheffers DJ. 2003. Cytokinesis in bacteria. Microbiol Mol Biol Rev 67: 52-65.

Gerding MA, Liu B, Bendezu FO, Hale CA, Bernhardt TG, de Boer PA. 2009. Self-enhanced accumulation of FtsN at division sites and roles for other proteins with a SPOR domain (DamX, DedD, and RlpA) in Escherichia coli cell constriction. J Bacteriol 191: 7383-7401.

Goehring NW, Beckwith J. 2005. Diverse paths to midcell: assembly of the bacterial cell division machinery. Curr Biol 15: R514-R526. doi: 10.1016/j.cub.2005.06.038.

Goley ED, Yeh YC, Hong SH, Fero MJ, Abeliuk E, McAdams HH, Shapiro L. 2011. Assembly of the Caulobacter cell division machine. Mol Microbiol doi: 10.1111/j.1365-2958.2011.07677.x.

Gottesman S, Halpern E, Trisler P. 1981. Role of sulA and sulB in filamentation by lon mutants of Escherichia coli K-12. J Bacteriol 148: 265-273.

Handler AA, Lim JE, Losick R. 2008. Peptide inhibitor of cytokinesis during sporulation in Bacillus subtilis. Mol Microbiol 68: 588-599.

Harper JW, Elledge SJ. 2007. The DNA damage response: ten years after. Mol Cell 28: 739-745.

Hartwell LH, Weinert TA. 1989. Checkpoints: controls that ensure the order of cell cycle events. Science 246: 629-634.

Hemm MR, Paul BJ, Schneider TD, Storz G, Rudd KE. 2008. Small membrane proteins found by comparative genomics and ribosome binding site models. Mol Microbiol 70: 1487-1501.

Hemm MR, Paul BJ, Miranda-Rios J, Zhang A, Soltanzad N, Storz G. 2010. Small stress response proteins in Escherichia coli: proteins missed by classical proteomic studies. I Bacteriol 192: 46-58.

Hill TM, Sharma B, Valjavec-Gratian M, Smith J. 1997. sfiindependent filamentation in Escherichia coli is lexA dependent and requires DNA damage for induction. I Bacteriol 179: 1931-1939.

Holtje JV. 1998. Growth of the stress-bearing and shape-maintaining murein sacculus of Escherichia coli. Microbiol Mol Biol Rev 62: 181-203.

Huisman O, D'Ari R. 1981. An inducible DNA replication-cell division coupling mechanism in E. coli. Nature 290: 797-799.

Justice SS, Garcia-Lara J, Rothfield LI. 2000. Cell division inhibitors SulA and MinC/MinD block septum formation at different steps in the assembly of the Escherichia coli division machinery. Mol Microbiol 37: 410-423.

Karimova G, Dautin N, Ladant D. 2005. Interaction network among Escherichia coli membrane proteins involved in cell division as revealed by bacterial two-hybrid analysis. I Bacteriol 187: 2233-2243.

Kawai Y, Ogasawara N. 2006. Bacillus subtilis EzrA and FtsL synergistically regulate FtsZ ring dynamics during cell division. Microbiology 152: 1129-1141.

Kawai Y, Moriya S, Ogasawara N. 2003. Identification of a protein, YneA, responsible for cell division suppression during the SOS response in Bacillus subtilis. Mol Microbiol 47: 1113-1122.

Krogh A, Larsson B, von Heijne G, Sonnhammer EL. 2001. Predicting transmembrane protein topology with a hidden Markov model: application to complete genomes. J Mol Biol 305: $567-580$.

Laub MT, McAdams HH, Feldblyum T, Fraser CM, Shapiro L. 2000. Global analysis of the genetic network controlling a bacterial cell cycle. Science 290: 2144-2148.

Laub MT, Chen SL, Shapiro L, McAdams HH. 2002. Genes directly controlled by CtrA, a master regulator of the Caulobacter cell cycle. Proc Natl Acad Sci 99: 4632-4637. 
Little JW, Mount DW. 1982. The SOS regulatory system of Escherichia coli. Cell 29: 11-22.

Lutkenhaus J. 2007. Assembly dynamics of the bacterial MinCDE system and spatial regulation of the $\mathrm{Z}$ ring. Annu Rev Biochem 76: 539-562.

Lutkenhaus J, Addinall SG. 1997. Bacterial cell division and the Z ring. Annu Rev Biochem 66: 93-116.

Mercer KL, Weiss DS. 2002. The Escherichia coli cell division protein FtsW is required to recruit its cognate transpeptidase, FtsI (PBP3), to the division site. J Bacteriol 184: 904-912.

Mo AH, Burkholder WF. 2010. YneA, an SOS-induced inhibitor of cell division in Bacillus subtilis, is regulated posttranslationally and requires the transmembrane region for activity. J Bacteriol 192: 3159-3173.

Mohammadi T, van Dam V, Sijbrandi R, Vernet T, Zapun A, Bouhss A, Diepeveen-de Bruin M, Nguyen-Disteche M, de Kruijff B, Breukink E. 2011. Identification of FtsW as a transporter of lipid-linked cell wall precursors across the membrane. EMBO J 30: 1425-1432.

Moll A, Thanbichler M. 2009. FtsN-like proteins are conserved components of the cell division machinery in proteobacteria. Mol Microbiol 72: 1037-1053.

Mukherjee A, Cao C, Lutkenhaus J. 1998. Inhibition of FtsZ polymerization by SulA, an inhibitor of septation in Escherichia coli. Proc Natl Acad Sci 95: 2885-2890.

Ogino H, Teramoto H, Inui M, Yukawa H. 2008. DivS, a novel SOS-inducible cell-division suppressor in Corynebacterium glutamicum. Mol Microbiol 67: 597-608.

Opperman T, Murli S, Smith BT, Walker GC. 1999. A model for a umuDC-dependent prokaryotic DNA damage checkpoint. Proc Natl Acad Sci 96: 9218-9223.

Quardokus EM, Din N, Brun YV. 2001. Cell cycle and positional constraints on FtsZ localization and the initiation of cell division in Caulobacter crescentus. Mol Microbiol 39: 949-959.

Rico AI, Garcia-Ovalle M, Palacios P, Casanova M, Vicente M. 2010. Role of Escherichia coli FtsN protein in the assembly and stability of the cell division ring. Mol Microbiol 76: 760-771.

Spratt BG. 1977. Temperature-sensitive cell division mutants of Escherichia coli with thermolabile penicillin-binding proteins. J Bacteriol 131: 293-305.

Vicente M, Rico AI, Martinez-Arteaga R, Mingorance J. 2006. Septum enlightenment: assembly of bacterial division proteins. I Bacteriol 188: 19-27.

Weart RB, Lee AH, Chien AC, Haeusser DP, Hill NS, Levin PA. 2007. A metabolic sensor governing cell size in bacteria. Cell 130: 335-347.

White CL, Kitich A, Gober JW. 2010. Positioning cell wall synthetic complexes by the bacterial morphogenetic proteins MreB and MreD. Mol Microbiol 76: 616-633.

Wortinger M, Sackett MJ, Brun YV. 2000. CtrA mediates a DNA replication checkpoint that prevents cell division in Caulobacter crescentus. EMBO J 19: 4503-4512.

$\mathrm{Wu}$ LJ, Errington J. 2004. Coordination of cell division and chromosome segregation by a nucleoid occlusion protein in Bacillus subtilis. Cell 117: 915-925. 


\section{Erratum}

Genes \& Development 25: 1328-1343 (2011)

A DNA damage checkpoint in Caulobacter crescentus inhibits cell division through a direct interaction with FtsW Joshua W. Modell, Alexander C. Hopkins, and Michael T. Laub

In Figure 6C of this article, the fusion to T18 is indicated as "M2-SidA" but should be "FtsN." The figure legend and text are correct, and this error does not affect any statements or conclusions in the article. A corrected version of the figure is shown below, and the PDF of the article on the journal website has been corrected to reflect this change.

The authors apologize for any confusion this may have caused.

A

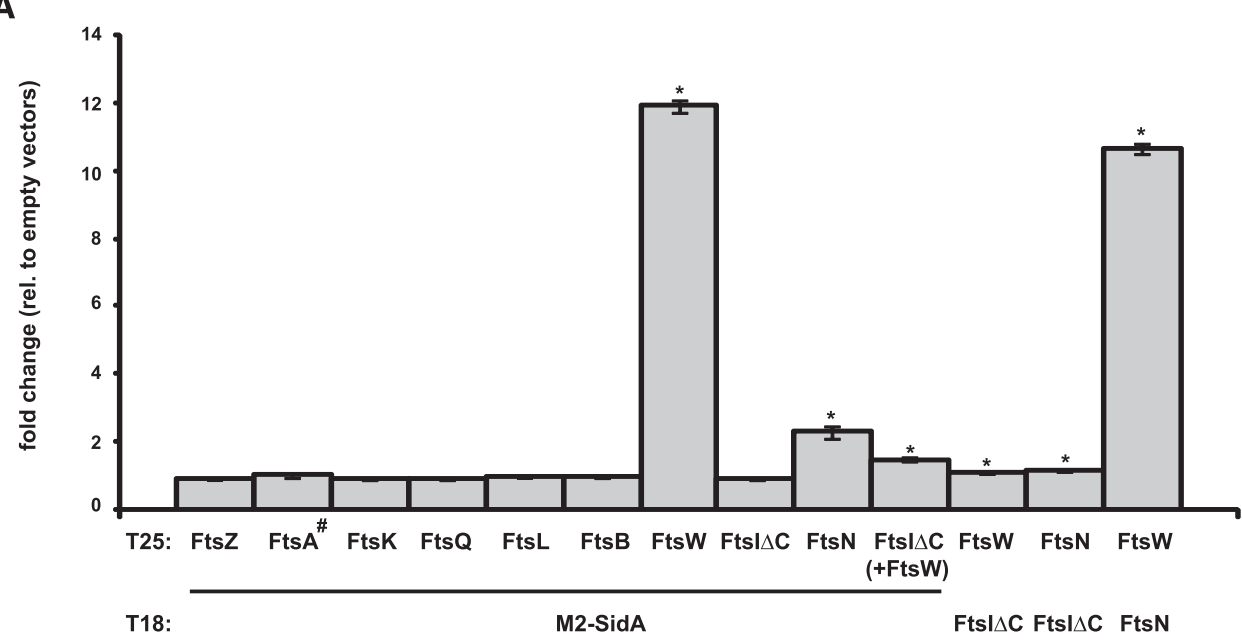

B

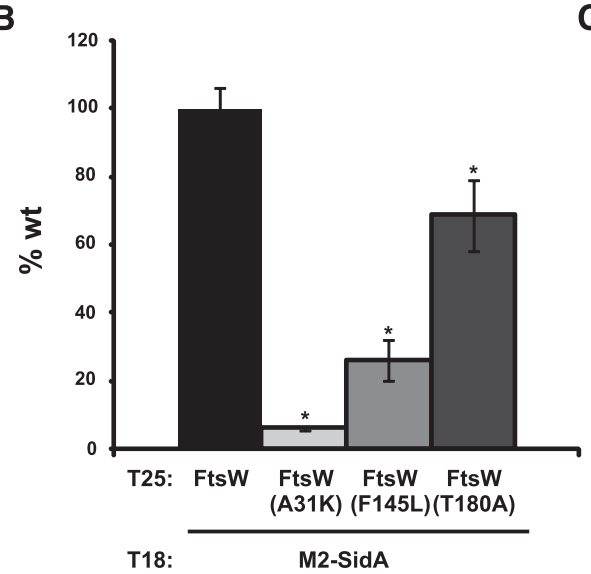

C

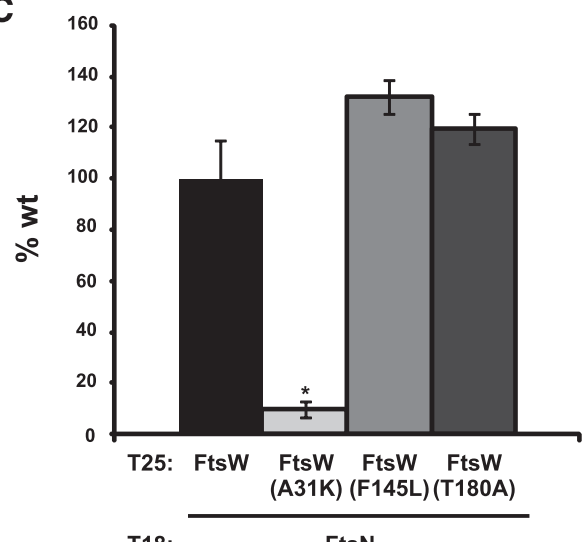

T18:

FtsN 


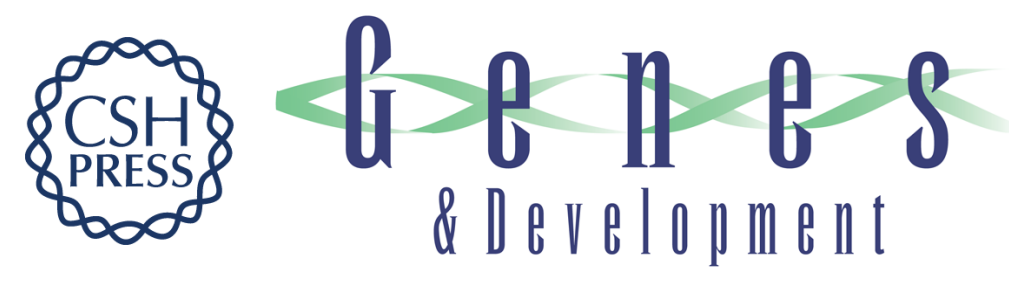

\section{A DNA damage checkpoint in Caulobacter crescentus inhibits cell division through a direct interaction with FtsW}

Joshua W. Modell, Alexander C. Hopkins and Michael T. Laub

Genes Dev. 2011, 25:

Access the most recent version at doi:10.1101/gad.2038911

\section{Supplemental http://genesdev.cshlp.org/content/suppl/2011/06/17/25.12.1328.DC1 \\ Material}

Related Content

A DNA damage checkpoint in Caulobacter crescentus inhibits cell division through a direct interaction with FtsW

Joshua W. Modell, Alexander C. Hopkins and Michael T. Laub

Genes Dev. August , 2011 25: 1662

References This article cites 52 articles, 19 of which can be accessed free at:

http://genesdev.cshlp.org/content/25/12/1328.full.html\#ref-list-1

Articles cited in:

http://genesdev.cshlp.org/content/25/12/1328.full.html\#related-urls

\section{License}

Email Alerting

Service

Receive free email alerts when new articles cite this article - sign up in the box at the top right corner of the article or click here.

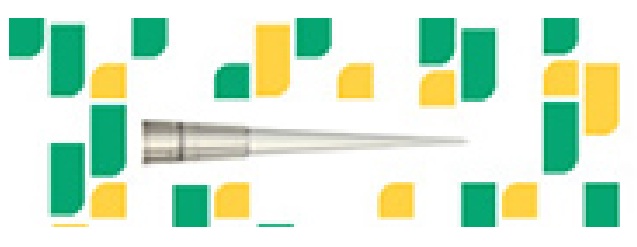

Focused on your science. 